\title{
Long distance movement of DIR1 and investigation of the role of DIR1-like during systemic acquired resistance in Arabidopsis
}

\author{
Marc J. Champigny ${ }^{1,2}$, Marisa Isaacs ${ }^{1}$, Philip Carella ${ }^{1}$, Jennifer Faubert ${ }^{1,2}$, Pierre R. Fobert ${ }^{2}$ and \\ Robin K. Cameron ${ }^{1 *}$
}

1 Department of Biology, McMaster University, Hamilton, ON, Canada

2 Plant Biotechnology Institute, Saskatoon, SK, Canada

\section{Edited by:}

Xin Li, University of British

Columbia, Canada

\section{Reviewed by:}

Hailing Jin, University of California,

Riverside, USA

Jyoti Shah, University of North

Texas, USA

${ }^{*}$ Correspondence:

Robin K. Cameron, Department of

Biology, McMaster University,

1280 Main St. West, Hamilton,

ON L8S 4K1, Canada

e-mail: rcamero@mcmaster.ca
DIR1 is a lipid transfer protein (LTP) postulated to complex with and/or chaperone a signal(s) to distant leaves during Systemic Acquired Resistance (SAR) in Arabidopsis. DIR1 was detected in phloem sap-enriched petiole exudates collected from wild-type leaves induced for SAR, suggesting that DIR1 gains access to the phloem for movement from the induced leaf. Occasionally the defective in induced resistance1 (dir1-1) mutant displayed a partially SAR-competent phenotype and a DIR1-sized band in protein gel blots was detected in dir1-1 exudates suggesting that a highly similar protein, DIR1-like (At5g48490), may contribute to SAR. Recombinant protein studies demonstrated that DIR1 polyclonal antibodies recognize DIR1 and DIR1-like. Homology modeling of DIR1-like using the DIR1-phospholipid crystal structure as template, provides clues as to why the dir1-1 mutant is rarely SAR-competent. The contribution of DIR1 and DIR1-like during SAR was examined using an Agrobacterium-mediated transient expression-SAR assay and an estrogen-inducible DIR1-EGFP/dir1-1 line. We provide evidence that upon SAR induction, DIR1 moves down the leaf petiole to distant leaves. Our data also suggests that DIR1-like displays a reduced capacity to move to distant leaves during SAR and this may explain why dir1-1 is occasionally SAR-competent.

Keywords: DIR1, systemic acquired resistance, DIR1-like, lipid transfer protein, long distance signaling

\section{INTRODUCTION}

Plants respond to pathogen infection locally at the individual cell level and can acquire resistance in tissues distant from the initial site of infection. Acquired resistance in plants was originally documented more than 70 years ago (Chester, 1933) and the term Systemic Acquired Resistance (SAR) was first used by Ross (1961). SAR is defined as a defense response induced by certain local infections resulting in broad-spectrum resistance in distant tissues to normally virulent pathogens (Kuć, 1982).

Research using tobacco, cucumber and Arabidopsis demonstrated that the SAR response occurs in stages that include induction, movement of a long distance signal(s), perception of the signal(s) which primes the plant for the manifestation stage in which the plant responds to normally virulent pathogens in a resistant manner [reviewed in Champigny and Cameron (2009)]. Induction of SAR is initiated when a necrotizing pathogen infects a leaf and results in either the formation of a localized hypersensitive response (HR) and local resistance, or in disease-induced necrosis (Kuć, 1982). However, recent studies in tobacco (Liu et al., 2010a) and Arabidopsis (Mishina and Zeier, 2007) suggest that cell death is not required to induce SAR.

Grafting experiments with cucumber provided evidence that a long distance signal moves from induced rootstocks to distant scions (Jenns and Kuć, 1979). Moreover, girdling with hot cotton wool in cucumber (Guedes et al., 1980) or by removing the stem sheath in tobacco (Tuzun and Kuć, 1985) prevented signal transport to distant leaves, suggesting that the SAR long distance signal(s) moves via the phloem. However, these techniques reduce both phloem and cell-to-cell movement, indicating that the SAR long distance signal could travel using either or both transportation routes. Source-sink relationships (orthostichies) in the Arabidopsis rosette were investigated in relation to SARcompetence (Kiefer and Slusarenko, 2003). Movement of the SAR signal from induced to distant leaves to establish and manifest SAR as measured by PR-1 expression and reduced growth of Pseudomonas syringae pv. tomato (Pst), indicated that upper leaves in and outside the orthostichy of the lower induced leaf were also SAR-competent. These data suggest that the Arabidopsis long distance SAR signal(s) moves via the phloem and other means, perhaps cell-to-cell.

The discovery that salicylic acid (SA) levels rise in phloem exudates of induced tobacco (Malamy et al., 1990) and cucumber (Métraux et al., 1990) led to the hypothesis that SA may be a SAR long distance signal (Uknes et al., 1992). Cucumber leaf detachment experiments (Rasmussen et al., 1991) as well as grafting studies with transgenic tobacco that accumulates little SA strongly suggested that $\mathrm{SA}$ is not a SAR long distance signal, but is required in distant tissue during the priming and manifestation stages of the SAR pathway (Gaffney et al., 1993; Vernooij et al., 1994; Pallas et al., 1996). 
The establishment phase of SAR involves the perception of the mobile signal(s) in distant tissue, resulting in a primed state that is correlated with the accumulation of inactive protein kinases and chromatin modifications in SAR-associated gene promoters and is thought to provide the molecular memory of priming [reviewed in Conrath (2011)]. Manifestation of SAR is associated with the expression and activity of a set of $P R$ genes (van Loon and van Strien, 1999). The rapid and abundant accumulation of these defense proteins during the manifestation stage may be the molecular basis for systemic resistance [reviewed in Champigny and Cameron (2009), Shah and Zeier (2013)].

A number of genes acting at the initiation or terminal stages of the SAR pathway have been identified [reviewed in Durrant and Dong (2004), Vlot et al. (2008)]. Key among these is NPR1, whose function is required for the SA-dependent expression of PR proteins [reviewed in Durrant and Dong (2004)]. Recent work suggests that NPR1 is a receptor for SA (Wu et al., 2012) and that the paralogous proteins NPR3 and NPR4 may also act as SA receptors in Arabidopsis leaves during the manifestation stage of SAR (Fu et al., 2012). Information about long distance signaling during SAR was obtained from the study of dir1-1 (defective in induced resistance 1). Petiole exudates, enriched for phloem sap and/or molecules that move cell-to-cell down the petiole, collected from induced, but not mock-inoculated wild-type leaves were effective in eliciting expression of $P R-1$ when infiltrated into wild-type or dirl-1 plants, indicating that long-distance SAR signals are present in wild-type exudates and dirl-1 can perceive these signals. Exudates similarly collected from dir1-1 leaves did not induce $P R-1$ expression in wild-type leaves, suggesting that dir1-1 is defective either in the synthesis of the SAR mobile signal or its long-distance transport to distant leaves (Maldonado et al., 2002). These data and the fact that DIR1 encodes a putative lipid transfer protein (LTP) led to the hypothesis that DIR1 is involved in long distance signaling and may chaperone a lipid signal to distant leaves during SAR (Maldonado et al., 2002).

LTPs are ubiquitous in plants and are associated with many developmental and stress response processes (Yeats and Rose, 2008). The structures of a number of LTPs have been determined, revealing that they possess a consensus motif of eight cysteine residues engaged in four disulphide bridges forming a central hydrophobic cavity which can bind long fatty acid chains (Yeats and Rose, 2008). Lascombe et al. (2006, 2008) determined the structure and lipid binding properties of DIR1 expressed in the yeast Pichia pastoris using fluorescence and Xray diffraction. DIR1 shares some structural and lipid binding properties with the LTP2 family but unique to DIR1 is its ability to bind two monoacylated phospholipids in vitro. Studies of glycerolipid biosynthesis mutants (Nandi et al., 2004; Chaturvedi et al., 2008) also suggest that a lipid-derived molecule is a long distance SAR signal. Other studies indicate that methyl salicylate (MeSA) azelaic acid (AA), glycerol-3-phospate (G3P)derived factor, and dehydroabietinal (DA) may also be SAR long distance signals (Park et al., 2007; Vlot et al., 2008; Jung et al., 2009; Chanda et al., 2011; Chaturvedi et al., 2012). The SAR-promoting role of these small molecules requires the presence of DIR1 protein as demonstrated by the inability of G3P,
AA, MeSA, or DA to induce SAR in dir1-1, suggesting that one or more of these molecules may be physiological ligands of DIR1. Overexpression/SAR studies in dir1-1 demonstrated that two tobacco DIR1 orthologs are functionally redundant to Arabidopsis DIR1 and thus DIR1 is important for SAR in both Arabidopsis and tobacco (Liu et al., 2011a). Furthermore, a putative tomato DIR1 ortholog was identified in untreated tomato phloem by protein gel blot analysis, however its importance in the tomato SAR response has yet to be established (Mitton et al., 2009).

Expression and localization of DIR1 using DIR1pro:GUS and DIR1 pro:DIR1-GUS fusion lines (Champigny et al., 2011) demonstrated that DIR1 is expressed in seedlings and flowers, and ubiquitously in untreated or mock-inoculated mature leaf cells including phloem sieve elements and companion cells. Intercellular washing fluid (IWF) experiments and subcellular localization of transiently expressed DIR1:EGFP in tobacco indicated that DIR1's ER signal sequence targets it for secretion to the cell wall. Interestingly, a transgenic line expressing DIR1 without its signal sequence in which DIR1 accumulates in the cytosol rescued the dir1-1 SAR defect, suggesting that a cytosolic pool of DIR1 is important for SAR (Champigny et al., 2011).

Previously we hypothesized that DIR1 moves to distant tissues during SAR (Maldonado et al., 2002) and recently demonstrated that DIR1 is well situated to participate in long distance signaling as it is expressed in companion cells and sieve elements (Champigny et al., 2011). Numerous reviews (Durrant and Dong, 2004; Parker, 2009; Dempsey and Klessig, 2012) present models in which DIR1 translocates to distant tissues during SAR. Chanda et al. (2011) provide evidence for the movement of ectopically expressed Arabidopsis DIR1-EGFP in N. benthamiana plants in response to G3P infiltration. However, the movement of native DIR1 during biologically induced SAR has not been demonstrated. Therefore, we conducted experiments to determine if DIR1 possesses the key characteristic of a SAR long distance signal: the ability to move from induced to distant leaves during the SAR response. We also sought to distinguish the role of DIR1 and the highly similar DIR1-like protein by developing and using a transient Agrobacterium-SAR assay and an estrogen-inducible DIR1-EGFP/dir1-1 line.

\section{RESULTS DIR1 IS DETECTED IN PETIOLE EXUDATES COLLECTED FROM LEAVES INDUCED FOR SAR}

Using petiole exudate infiltration experiments, Maldonado et al. (2002) demonstrated that SAR-inducing signals are present in wild-type, but not dir1-1 plants, leading to the hypothesis that DIR1, a putative LTP, binds a lipid or hydrophobic molecule and participates in the long distance signaling stage of SAR. If DIR1 chaperones a hydrophobic signal(s) or is part of a signal complex [DIR1 plus hydrophobic molecule(s)] that translocates to distant tissue during SAR, then it should be possible to detect DIR1 in petiole exudates collected throughout the SAR induction stage. Mock-inoculated leaves and leaves induced for SAR with Pst (avrRpt2) were collected from wild-type (Ws-2) and dir1-1 mutant plants at $10 \mathrm{~h}$ post inoculation (hpi), quickly surface sterilized and immersed in $1 \mathrm{mM}$ EDTA to prevent sieve 
element blockage at the cut petiole ends (King and Zeevaart, 1974). Petioles were allowed to exude over $44 \mathrm{~h}$. Petiole exudate protein levels were determined, followed by concentration by lyophilization and protein gel blot analysis with an anti-DIR1 polyclonal antibody (Maldonado et al., 2002). Exudates collected from mock-inoculated leaves consistently contained less protein per exudate $\left(\sim 3 \mu \mathrm{g} \mathrm{ml}^{-1}\right)$ compared to exudates collected from leaves induced for SAR $\left(\sim 30 \mu \mathrm{g} \mathrm{ml}^{-1}\right)$, suggesting that additional proteins enter the phloem during SAR induction (Figure S1). A DIR1 antibody signal of approximately $15 \mathrm{kDa}$ was detected in Ws exudates collected from leaves induced for SAR, but not in mock-inoculated Ws or dir1-1 exudates (Figure 1A). The absence of DIR1 antibody signals in exudates collected from mock-inoculated leaves is consistent with experiments done with untreated Arabidopsis petiole exudates performed by Guelette et al. (2012). A DIR1 signal is not present at detectable levels in exudates prior to the induction of SAR suggesting that DIR1 protein moves out of the leaf blade and down the petiole during the SAR induction stage. Later experiments (Figures 5, 6) indicate that Agrobacterium tumefaciens does not induce SAR and does not elicit the accumulation of DIR1 antibody signals (Agroinoculated, followed by mock-inoculated treatments). Therefore, the DIR1 antibody signals observed in petiole exudates collected from SAR-induced leaves are specific to the SAR response.

If DIR1 protein is moving down the petiole during SAR induction, collection of exudates at different times after induction should provide information about the length of time it takes DIR1 to move. Exudates from mock-inoculated leaves and leaves induced for SAR were collected from Ws and a DIR1GUS transgenic line (DIR1pro:DIR1-GUS-29/dir1-1, Champigny et al., 2011) to follow DIR1 movement using protein gel blot analysis and assaying for GUS activity of the DIR1-GUS fusion protein. At $8 \mathrm{hpi}$, mock-inoculated and SAR-induced leaves were collected and allowed to exude for $1 \mathrm{~h}$, transferred to new tubes and allowed to exude from 1 to $15 \mathrm{~h}$, transferred again and allowed to exude for 15-20 h, then 20-25 and finally $25-44 \mathrm{~h}$, followed by protein gel blot analysis (Figure 1B). The $0-1$ h exudates were collected to demonstrate that the DIR1 signal observed was not due to proteins leaking from wounded and dying cells before the wound response sealed the non-phloem cells at the cut petiole ends. A DIR1 signal of $\sim 15 \mathrm{kDa}$ was not observed in any of the mock-inoculated samples or in the $0-1 \mathrm{~h}$ exudates collected from leaves induced for SAR. DIR1 protein was observed in SARinduced exudates at 20-25 hpi in Ws and at 1-15 and 15-20 hpi in the DIR1-GUS line. Bands of $\sim 7$ and $15 \mathrm{kDa}$ were observed in exudates from the DIR1-GUS line (Figure 1B). Mature DIR1 is comprised of 77 amino acids with a predicted molecular weight of $\sim 7 \mathrm{kDa}$ (Lascombe et al., 2008). The presence of 7 and $\sim 15 \mathrm{kDa}$ bands suggests that DIR1 is present in petiole exudates in both monomeric and dimeric forms. Typically, the $15 \mathrm{kDa}$ form was observed in IWFs (Figure S2). During SDS-PAGE, samples are heated in SDS to disrupt non-covalent bonds leading to protein denaturation. A reducing agent such as dithiothreitol (DTT) is added to reduce covalent disulfide bonds, however some disulfide bonds are not broken at the DTT concentrations normally used in denaturing SDS-PAGE gels (5 mM DTT) (Mahler et al., 2009). Therefore, exudates collected from an over-expression line
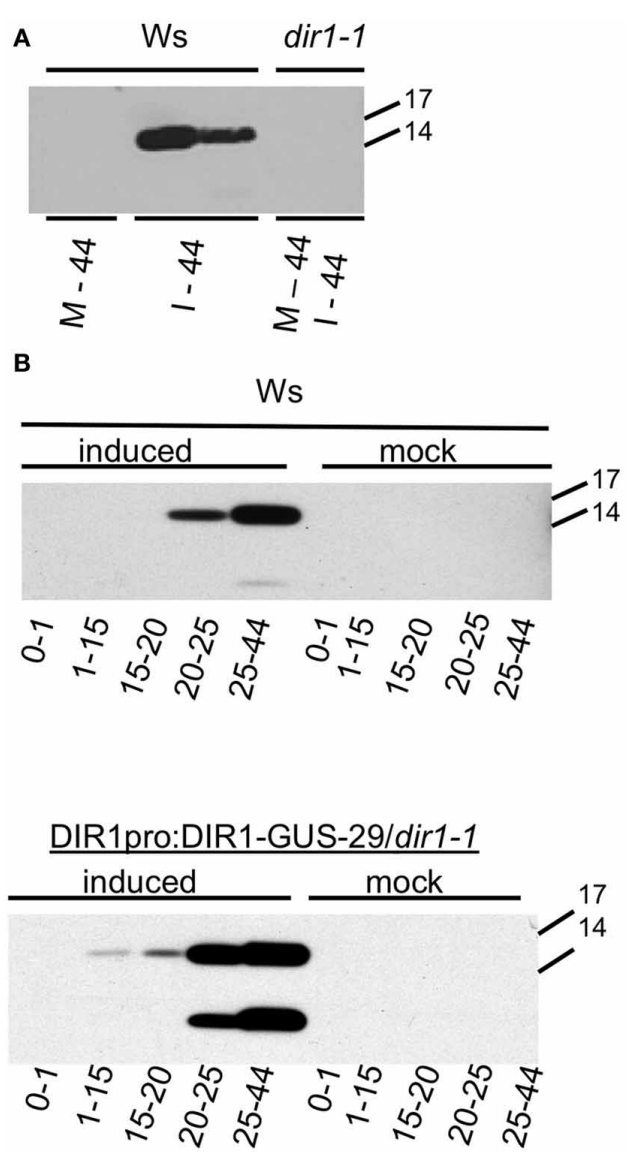

C

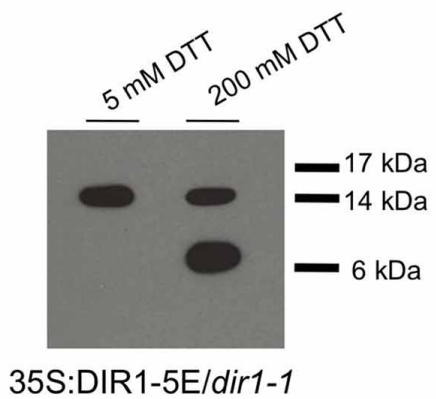

FIGURE 1 | Detection of DIR1 in petiole exudates. (A) Ws and dir1-1 plants were mock-inoculated or inoculated with SAR-inducing Pst (avrRpt2) $\left(10^{6} \mathrm{cfu} \mathrm{m}^{-1}\right)$. Seven petioles per tube were allowed to exude starting at $\sim 8$ hpi until 44 hpi (= one exudate). Each exudate was lyophilized and subjected to protein gel blot analysis with the DIR1 antibody. M-44= mock-inoculated petioles exuded for $44 \mathrm{hpi}$, l-44 = petiole from leaves induced for SAR exuded for $44 \mathrm{hpi}$. (B) Ws and DIR1 pro:DIR1-GUS-29/dir1-1 were mock-inoculated or induced for SAR with Pst (avrRpt2) $\left(10^{6} \mathrm{cfu} \mathrm{m}{ }^{-1}\right)$, petiole exudates were collected from $\sim 8 \mathrm{hpi}$ for $0-1 \mathrm{~h}$, then transferred to another tube for 1-15 h, transferred again for 15-20, then for 20-25 and 25-44 hpi (denoted by arrows). Exudates were lyophilized and subjected to SDS-PAGE. (C) Exudates collected over 44 hpi with SAR-inducing Pst (avrRpt2) $\left(10^{6} \mathrm{cfu} \mathrm{ml}^{-1}\right)$ from the DIR1 overexpression line (35S:DIR1-5E/dir1-1) were lyophyilized and resuspended in 5 or $200 \mathrm{mM}$ dithiothreitol (DTT) and subjected to protein gel blot analysis with the DIR1 antibody. Protein molecular weight markers are indicated $(17,14,6 \mathrm{kDA})$. $(\mathbf{A}, \mathbf{B})$ have been repeated with similar results three times. $(\mathbf{C})$ has been repeated once with similar results. 
(35S:DIR1/dir1-1) were denatured in freshly prepared sample buffer containing either 5 or $200 \mathrm{mM}$ DTT before protein gel blot analysis. A DIR1 band of $\sim 15 \mathrm{kDa}$ was observed in $5 \mathrm{mM}$ DTT and both 7 and $15 \mathrm{kDa}$ bands were observed when the exudate was incubated in $200 \mathrm{mM}$ DTT (Figure 1C), suggesting that the $15 \mathrm{kDa}$ signal represents a DIR1-containing dimer held together by disulfide bonds.

A DIR1-GUS fusion protein $(7$ or $15+68 \mathrm{kDa}=75$ or 83 ) was not detected in petiole exudates (Figure 1B) or in IWFs collected from the DIR1-GUS line (Figure S1). In a few experiments, a $\sim 75 \mathrm{kDa}$ DIR1-GUS band was detected in whole leaf extracts from DIR1-GUS lines using anti-DIR1 and anti-GUS antibodies (Figure S3). Observing low levels of DIR1-GUS in leaf extracts is consistent with our previous results in which a DIR1 signal was not detected in wild-type Ws leaf extracts (Maldonado et al., 2002). These observations, and the fact that GUS activity was detected intracellularly in leaf cells in both the DIR1pro:GUS as well as the DIR1-GUS fusion lines (Champigny et al., 2011) suggests that GUS is cleaved from DIR1 after secretion to the cell wall and/or at some point during SAR induction.

\section{A DIR1 SIGNAL IS SOMETIMES DETECTED IN dir1-1 PETIOLE EXUDATES FROM SAR-INDUCED LEAVES}

In some exudate-protein gel blot experiments, a DIR1-sized band was observed in exudates collected from dirl-1 leaves induced for SAR. This was observed in experiments similar to Figure 1A in which petioles exuded from 8 to $44 \mathrm{~h}$, or in time course experiments similar to those shown in Figure 1B. A representative experiment is displayed in Figure 2A in which a DIR1-antibody signal was detected in exudates collected from a number of SAR-induced plants including dir1-1. Genotyping ruled out seed contamination or loss of the T-DNA insertion in the dirl-1 gene during self-fertilization over a number of generations, indicating that the DIR1 antibody signal in dir1-1 exudates is not due to a wild-type DIR1 allele (data not shown). We also considered that the DIR1 signal observed in dir1-1 could be the result of a cross-reactive protein accumulating in exudates due to EDTAinduced tissue softening causing cell leakage along the length of submerged petioles (Hepler, 2005). To avoid this issue, we modified the petiole exudate collection method by shortening the exudation time to reduce leakage from petiole cells during exudation.

As shown in Figure 2B, exudate collection began and ended at various times after inoculation $(0-1 \mathrm{~h}, 1-14,14-20,20-23$, 23-38) of dir1-1 and the dir1-1 transgenic lines (35S:DIR $1^{\Delta 1-25}$ GUS-5, DIR1pro:DIR1-GUS-29, 35S:DIR1-5E), followed by protein gel blot analysis. Mock-inoculated exudates contained no DIR1 signal (data not shown), while a DIR1 band of $\sim 15 \mathrm{kDa}$ was observed in the 14-20, 20-23, and 23-38 hpi exudates in dirl-1 and the transgenic lines (35S:DIR $1^{\Delta 1-25}-$ GUS-5, DIR1pro:DIR1-GUS-29, 35S:DIR1-5E). The timing of the appearance of the protein gel blot signal was similar in the transgenics and in $\operatorname{dir1-1}$ and no signal was detected in the early exudates (0-1, 1-14 hpi). Even though the same pattern was observed in dir 1-1 and transgenic exudates, dir1-1 was SAR-defective in this experiment, while the transgenic lines were SAR-competent (SAR

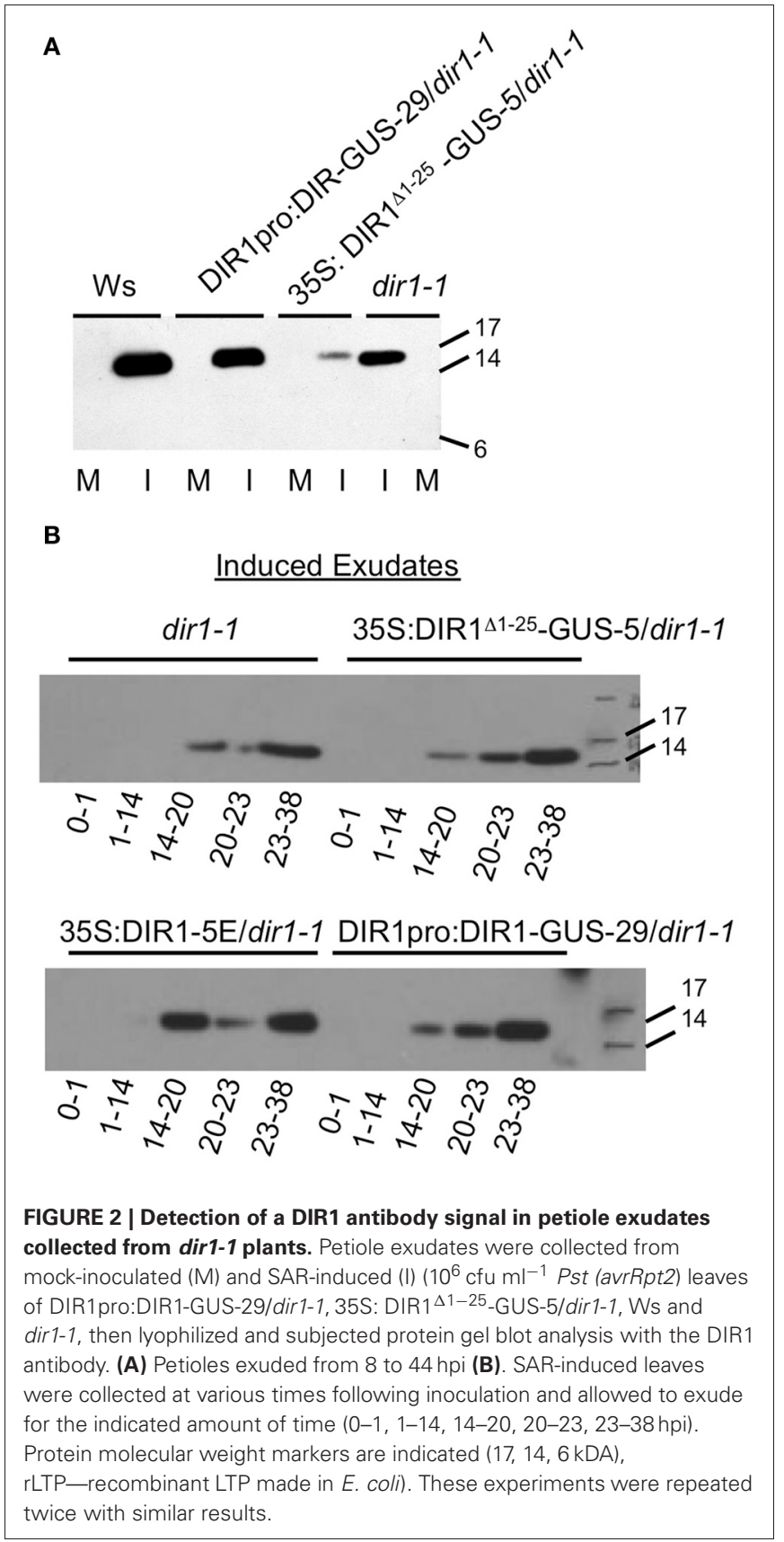

assays reported in Figure 6 in Champigny et al., 2011). Because we observed a DIR1 antibody signal in dirl-1 using short and long exudation methods, we hypothesize that the $15 \mathrm{kDa}$ DIR1antibody signal in SAR-induced dir1-1 results from the movement of a DIR1-like protein down the petiole where it exudes from sieve elements at the petiole ends.

In support of this hypothesis, dirl-1 was modestly or partially SAR-competent in some experiments, such that plants induced with Pst (avrRpt2) supported modestly lower bacterial levels compared to mock-inoculated dir1-1; an example is presented in Figure 3A. Of 30 SAR assays performed with dir1-1 in our former lab at the University of Toronto over 7 years ('96-'02), dir1-1 
A

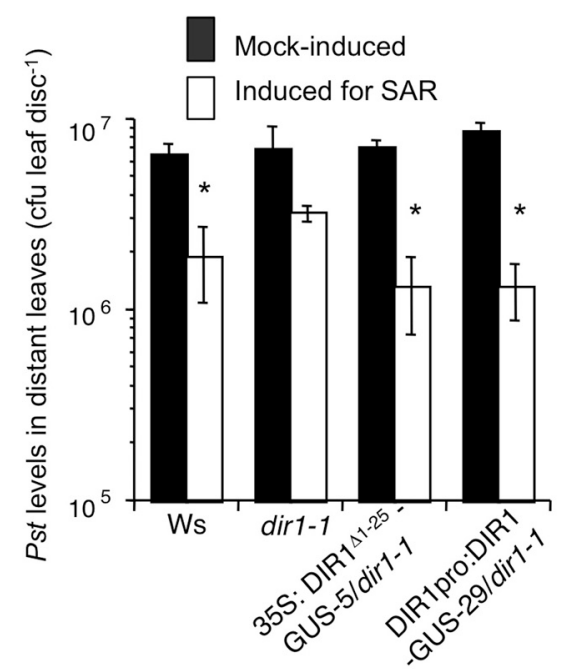

B

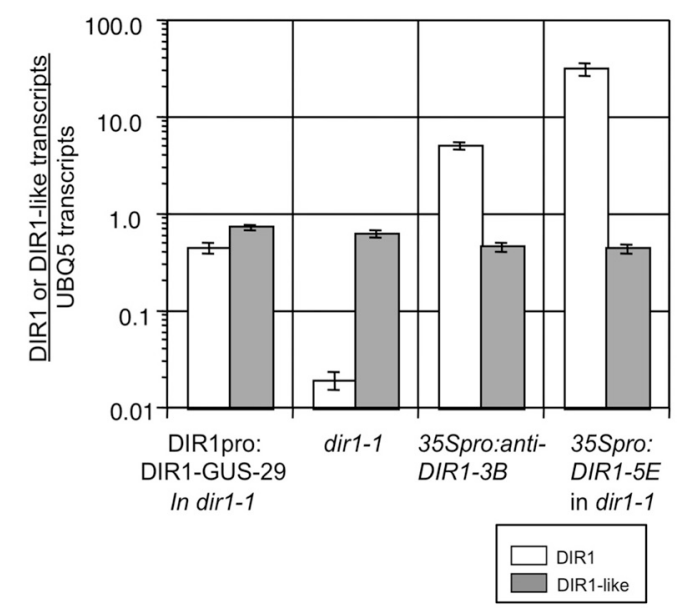

C

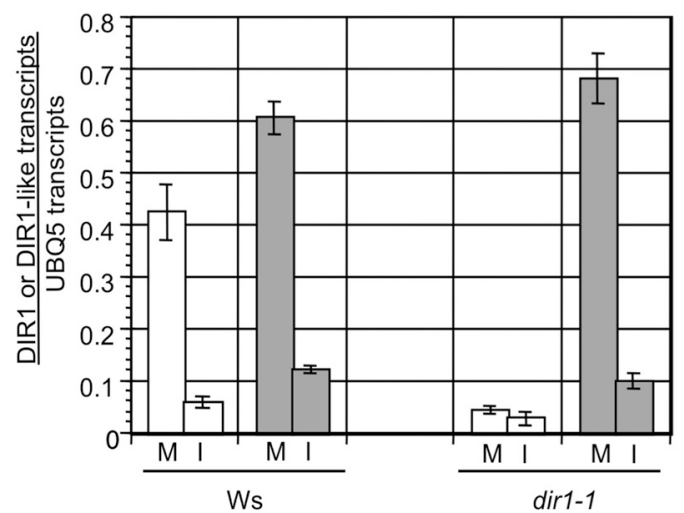

FIGURE 3 | A partial SAR response is sometimes observed in dir1-1. (A) SAR assays were conducted on Ws, dir1-1, DIR1pro:DIR1-GUS-29/dir1-1 and 35S: DIR1 ${ }^{\Delta 1-25}$-GUS-5/dir1-1 by inoculating with $10 \mathrm{mM} \mathrm{MgCl}_{2}$ (mock-induced) or inducing for SAR with Pst (avrRpt2) (SAR-induced) in 1-2 lower leaves, followed by challenge inoculation with virulent Pst in distant leaves 2 days later. Bacterial levels were determined in challenged leaves 3 dpi. Asterisks $\left({ }^{*}\right)$ denote a significant difference (student's $t$-test, $p<0.05$ ) in bacterial levels between challenged distant leaves of mock- and

(Continued)

\section{FIGURE 3 | Continued}

SAR-induced plants. These experiments were repeated numerous times and a partial SAR response was occasionally observed in dir 1-1 (see text for details). Expression of DIR1 and DIR1-like genes. Real-time RT-PCR analysis was performed using 3 week-old Arabidopsis leaves. Expression of DIR1 is represented by white bars and expression of DIR1-like is represented by gray bars. Absolute quantification of transcripts followed the method of Rutledge and Stewart (2008). Error bars represent the standard deviation of four measurements. (B) Expression of DIR1 and DIR1-like genes in untreated leaves collected from DIR1 pro:DIR1-GUS-29/dir1-1, dir1-1, 35S:antisenseDIR1-3B/Ws and 35S:DIR1-5E/dir1-1. Note the logarithmic scale and PCR primers used do not distinguish between wild-type DIR1 transcript and the antisense version. (C) Expression of DIR1 and DIR1-like genes in mock-inoculated (M) and SAR-induced (I) leaves $\left(10^{6} \mathrm{cfu} \mathrm{ml}^{-1}\right.$ Pst-avrRpt2) harvested at 10 hpi. Experiments were performed twice using real-time RT-PCR.

was modestly SAR-competent in two of 30 statistically significant experiments (student's $t$-test) or $6.7 \%$ of the time. Of 16 SAR assays performed at McMaster over 4 years ('03-'06), dir1-1 was modestly SAR-competent in 3 of 16 statistically significant experiments ( $t$-test) or $18.8 \%$ of the time. These data collected over many years in two different labs led us to speculate that a DIR1-like protein encoded in the Arabidopsis genome could be responsible for the DIR1-sized band observed in dir1-1 exudates and this DIR1-like protein may sometimes compensate for the SAR defect in dir1-1.

\section{IDENTIFICATION OF A DIR1-LIKE GENE}

In our experiments at the University of Toronto and McMaster, no event or environmental factor could be identified as the cause of the modestly SAR-competent phenotype in dir1-1 observed in some experiments. Therefore, we hypothesized that environmental conditions such as different growth chambers and/or water supply at McMaster University may have been responsible for observing a modest SAR response in dir1-1 more frequently compared to our lab at U. of Toronto. One explanation that could account for these observations is that a DIR1-like LTP may be present in the Arabidopsis genome and partially compensate for the dir1-1 SAR defect in some circumstances. Another possible explanation is that the T-DNA insertion in the $3^{\prime}$ untranslated region (UTR) of dir1-1 (Maldonado et al., 2002) does not completely abolish DIR1 expression such that a small amount of DIR1 is made in dirl-1 and this may be sufficient to elicit a partial SAR response on some occasions. When DIR1 was first identified (Maldonado et al., 2002), a highly similar LTP was not annotated in the Arabidopsis genome (TIGR 2 \& 3). A blast search of later genome releases revealed a highly similar gene to DIR1, At5g48490. Currently TAIR 10 indicates that Arabidopsis encodes at least 70 putative LTPs including DIR1 and At5g48490. The most statistically relevant BLAST hit using DIR1 (At5g48485) as the query sequence is At5g48490, the adjacent locus on chromosome 5. We refer to this gene as DIR1-like. Alignment of the coding and protein sequences indicated that these genes are highly conserved, exhibiting $71 \%$ sequence identity and $85 \%$ similarity at the amino acid level (Figure S4). Much of the observed variation is the result of differences in the poorly conserved ER signal peptides that are not present in the mature proteins. Analysis of 
the mature protein sequence revealed an $81 \%$ amino acid identity and $88 \%$ amino acid similarity.

\section{DIR1 PHYLOGENY}

DIR1-like and DIR1 likely arose through a tandem gene duplication as suggested by Boutrot et al. (2008) and their $88 \%$ amino acid sequence similarity (EMBOSS Needleman-Wunsch pairwise alignment EMBL-EBI) and tandem location on chromosome 5. A BLAST search of the Arabidopsis genome did not reveal other highly similar genes and a Needleman-Wunsch pairwise global alignment using EMBL-EBI confirmed that all other LTP2s share less than $52 \%$ sequence similarity compared to DIR1. Using various Brassicaceae family members, a phylogeny of putative DIR1 orthologs was constructed to add support to the hypothesis of tandem duplication as well as to determine the evolutionary node where DIR1 duplication occurred (Figures S5, S13). The Arabidopsis LTP2 gene (At5g38170) was used as an outgroup based on its low sequence similarity to DIR1 (37\%). Using phylogenetic analysis, two distinct groups are revealed, those with two DIR1 orthologs (Arabidopsis thaliana and lyrata) and those with one (Thellungiella salsuginea and Brassica rapa). Because only a single "DIR1-type" gene is present in T. salsuginea and B. rapa, a tandem duplication event occurring in the last common ancestor of $A$. thaliana and A. lyrata likely resulted in the DIR1 and DIR1-like paralogs. Recent species phylogenies of the Brassicaceae family (Schranz et al., 2007) and the DIR1 phylogeny presented here share a similar pattern providing further support for the DIR1 phylogeny. These results are consistent with Boutrot et al. (2008) and provide further information on the timing of DIR1 and DIR1-like duplication in the mustard family.

\section{EXPRESSION OF DIR1 AND DIR1-LIKE GENES}

If DIR1-like can occasionally compensate for the absence of DIR1 in the dir1-1 mutant, then DIR1-like should be expressed in dir1-1. DIR1 and DIR1-like expression was analyzed in plants of various genotypes at $10 \mathrm{~h}$ post-mock-inoculation or SAR induction with Pst (avrRpt2), or in untreated leaves. RNA was extracted from leaves of 3-week old plants, reverse transcribed to cDNA and subjected to real-time kinetic RT-PCR (Rutledge and Stewart, 2008) using primer pairs specific for DIR1 and DIR1-like.

Similar to previous studies (Maldonado et al., 2002; Champigny et al., 2011), modest expression of DIR1 in Ws was further reduced $\sim 10$-fold at $10 \mathrm{~h}$ post SAR-induction compared to mock-inoculated leaves (from 0.4 to 0.04 DIR1 transcripts per $U B Q 5)$, while few DIR1 transcripts $(<0.05$ per $U B Q 5)$ were detected in untreated, mock- or SAR-induced dir1-1 leaves (Figures 3B,C). As expected, DIR1 expression was elevated in untreated leaves of the $35 \mathrm{~S}$ promoter transgenic lines (35S:DIR1 in dir1-1, 35S:anti-senseDIR1-3B in Ws) compared to the DIR1 promoter line (DIR1pro:DIR1-GUS in dir1-1). DIR1-like transcript levels were similar in all genotypes (0.6-0.8 transcripts per $U B Q 5$, Figure 3B) indicating that expression of DIR1-like was not influenced by gene silencing effects from the DIR 1 transgenes or by the T-DNA insertion in dir1-1 near the DIR1-like locus. Similar to DIR1, DIR1-like was modestly expressed in Ws and its expression was further reduced $\sim 6$-fold in leaves induced for SAR compared to mock-inoculated Ws and dir1-1 leaves (Figures 3C, $\mathrm{S} 10 \mathrm{~B})$. This suggests that DIR1-like expression is suppressed by effectors secreted by Pst as was observed for DIR1 (Champigny et al., 2011). DIR1 and DIR1-like show similar expression profiles in untreated, mock or SAR-induced Ws plants and DIR1-like expression is unaffected in the dir1-1 mutant. Therefore, DIR1like is present in dir1-1 at DIR1 wild-type levels and could be responsible for the modest SAR response observed in dir1-1 in some experiments.

\section{HOMOLOGY MODELING OF DIR1-LIKE USING THE DIR1 CRYSTAL STRUCTURE}

A homology model of DIR1-like was produced by SWISSMODEL server (Peitsch, 1995; Schwede et al., 2003; Arnold et al., 2006; Kiefer et al., 2009) using the DIR1-phospholipid crystal structure (Lascombe et al., 2006, 2008) as a template to obtain clues to support the idea that DIR1-like sometimes compensates for the SAR defect in dir1-1. The Swiss-pdb viewer 4.0.1 (Guex and Peitsch, 1997) was used to compare the DIR1 structure and the DIR1-like protein model. The backbones of both proteins (lacking their ER signal sequences) were overlapped to observe vicinity information on conserved vs. non-conserved residues. Both proteins are very similar in terms of the arrangement of the five $\alpha$-helices and four disulphide bonds that produce the internal cavity of DIR1 (Figure 4A). A number of interesting differences were observed between DIR1 and the DIR1-like model and amino acid positions are based on the mature protein sequence lacking the signal peptide. Within the binding pocket, thirteen hydrophobic residues were within $3.8 \AA$ of the two phospholipids found in the internal cavity of the DIR1 crystal structure (Figure 4B). A phenylalanine is present at residue 40 in the internal cavity of DIR1, whereas a tyrosine residue was observed in DIR1-like (Figures 4C,D). The polar hydroxyl group present on DIR1-like's tyrosine may reduce the interaction with the phospholipid acyl chains at the bottom of the internal cavity or change the shape of the cavity by pulling toward the polar solution. Additionally, DIR1 has three polar amino acids (GLN9, ASN13, LYS16) located at the entrance of the internal cavity, while DIR1-like has only two (GLN9, ASN13) (Figures 4E,F). Lascombe et al. (2008) postulate that these three polar amino acids create a favorable environment for the hydrophilic phospholipid head groups. Loss of lysine at the cavity entrance in DIR1-like may affect its ability to form a stable interaction with a signal molecule(s) and reduce its capacity to contribute to SAR. Finally, DIR1-like possesses a putative SH3 interaction domain, PXXP, while DIR1 contains PXXPXXP at the same location on the protein surface (Figures 4G,H). SH3 interaction domains act as protein docking sites for transient protein-protein interactions and repeated PXXP motifs strengthen these interactions (Williamson, 1994). Therefore, it is possible that DIR1-like interacts less strongly with a binding partner and this may reduce its ability to contribute to SAR.

\section{THE POLYCLONAL DIR1 ANTIBODY RECOGNIZES DIR1-LIKE}

Homology modeling of DIR1 and DIR1-like suggest that DIR1like is structurally similar to DIR1. The extensive amino acid sequence similarity between the two proteins raised the possibility 


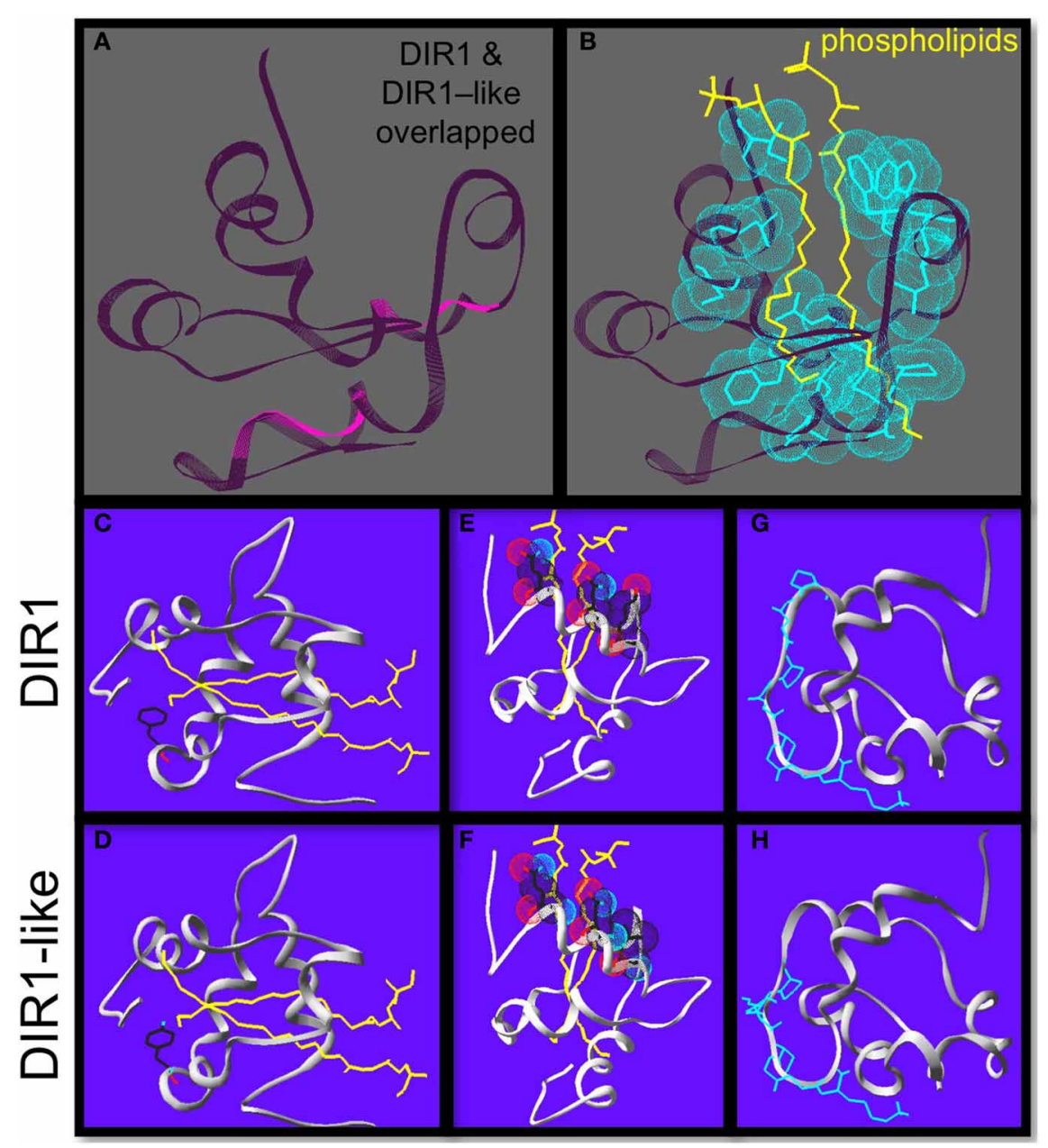

FIGURE 4 | Homology modeling reveals differences between DIR1 and DIR1-like protein structure. Homology modeling of DIR1-like protein using the DIR1 crystal structure as a template using the Swiss-pdb viewer 4.0.1 to compare the DIR1 structure and the DIR1-like protein model. (A) DIR1 protein backbone in dark purple is over-laid on the DIR1-like protein backbone in pink. (B) The two yellow phospholipids extend into the internal lipid binding pocket of DIR1. The 13 hydrophobic residues that make up the lipid binding pocket are highlighted with light blue van der waals forces. (C-F) Phospholipids in yellow, oxygen in light blue, nitrogen in red. DIR1 has a hydrophobic non-polar phenylalanine residue (C) while DIR1-like has a polar tyrosine residue at the same position (D). at the bottom of the internal lipid binding pocket. (E,D) The amino acids at the cavity entrance are shown with their van der waals forces. Three polar residues of DIR1 (D) compared to two of DIR1-like (E) cup the polar phosphate groups of the phospholipids. The putative SH3 binding motifs of DIR1 and DIR1-like are illustrated in light blue $(\mathbf{G}, \mathbf{H})$. that the DIR1 polyclonal antibody recognizes similar epitopes in both proteins. To test this idea, DIR1, DIR1-like and a representative Arabidopsis member of the LTP2 family (AT5G38170) were expressed as S-tagged proteins, extracted from Escherichia coli cells and subjected to protein gel blot analysis using DIR1 and S-tag antibodies. Arabidopsis LTP2 was chosen because its corresponding ortholog in wheat has been crystallized and has a general LTP2 structure similar to DIR1 in terms of the arrangement of $\alpha$ helices and four disulfide bridges (Hoh et al., 2005). Using the S-tag antibody, all three proteins were detected at the expected molecular weight of $\sim 13 \mathrm{kDa}$. Both DIR1 and DIR1-like were recognized by the DIR1 antibody (Figure S6) while LTP2 (AT5G38170) was not. These data indicate that the DIR1 antibody does recognize DIR1-like, but does not recognize an LTP in the same family.

\section{AGROBACTERIUM-MEDIATED TRANSIENT EXPRESSION/SAR ASSAY}

Our petiole exudate data (Figures 1, 2) suggests that DIR1 moves to distant leaves via the phloem, however, DIR1 is expressed constitutively in all living leaf and petiole cells (Champigny et al., 2011), making it difficult to distinguish between endogenous constitutive DIR1 expression and SAR-induced DIR1 movement. Therefore, an Agrobacterium tumefaciens-mediated transient expression/SAR assay (Agro-SAR) was developed to overcome this issue. By expressing DIR1 in just one dir1-1 leaf, followed by SAR induction of the same leaf, we can monitor DIR1 movement to distant leaves in the dir1-1 mutant which expresses negligible DIR1. Agrobacterium T-DNA constructs were created that encode EYFP or a DIR1-EYFP fusion protein containing the ER signal sequence under the control of the $35 \mathrm{~S}$ promoter. It takes approximately 4 days for Agrobacterium to transfer and transiently 
express its T-DNA containing the gene of interest in infected Arabidopsis cells (Wroblewski et al., 2005). Using RT-PCR, we observed low levels of DIR1-EYFP expression in Agrobacteriuminoculated leaves (Figure S7) consistent with other reports (Tsuda et al., 2012).

Before investigating DIR1-EYFP movement, we assessed the functionality of the Agro-SAR assay by testing the ability of transiently expressed DIR1-EYFP to rescue the SAR-defect in dir1-1. The Agro-SAR assay (illustrated in Figure S8) was performed as follows. Two leaves per plant were inoculated with the appropriate Agrobacterium strain, followed 4 days later by inoculation of the same leaf with SAR-inducing Pst (avrRpt2) or $10 \mathrm{mM} \mathrm{MgCl}_{2}$ (mock-inoculation). Two days later, distant leaves were inoculated with virulent Pst, followed by determination of Pst levels in the distant leaves 3 days later. Agrobacterium encoding 35S:EYFP or 35S:DIR1-EYFP was inoculated into dir1-1 or another dir1 mutant line (35S:antisenseDIR1-3B, Maldonado et al., 2002) followed 4 days later with the SAR assay. The SAR defect in both dir1-1 and the anti-sense DIR1 line was not rescued when EYFP was expressed, as demonstrated by high Pst levels in distant leaves (Figure 5A). Therefore, inoculation with Agrobacterium and/or expression of EYFP in planta did not rescue the SAR response in either DIR1-deficient genotype. DIR1-EYFP expression via Agrobacterium-mediated transient transformation rescued the SAR defect as demonstrated by a 3.5-fold or 5-fold reduction in Pst levels in SAR-induced vs. mock-inoculated dir1-1 or 35S:anti-senseDIR1-3B, respectively (Figure 5A). Our results indicate that Agrobacterium-mediated transient gene expression can be combined with the SAR assay. Additionally, expression of DIR1 in one leaf followed by SAR-induction is sufficient to rescue the SAR defect in dirl mutants.

During this experiment, petiole exudates were collected (Figure 5A) with the aim of monitoring the movement of fluorescent DIR1-EYFP in the dir1-1 background. Exudates were collected from leaves expressing empty T-DNA vector, EYFP or DIR1-EYFP that were either mock-inoculated or induced for SAR. Fluorescence levels were similar in all exudate samples examined, including exudates collected from untreated leaves (data not shown), suggesting that endogenous fluorescent plant compounds were being detected rather than EYFP fluorescence. RT-PCR data indicated that DIR1-EYFP was being expressed in leaves (Figure S7) suggesting that either insufficient DIR1-EYFP was made or EYFP was being cleaved from DIR1 in planta. To address this question, Agro-SAR assay exudates were subjected to protein gel blot analysis with DIR1 antibody to determine if the DIR1-EYFP fusion protein was present. Petiole exudates collected from dir1-1 leaves transiently expressing DIR1-EYFP that were also SAR-induced, contained a $\sim 7$ and $\sim 15 \mathrm{kDa}$ DIR1 signal, while mock-inoculated exudates contained no DIR1 signal (Figure 5B). A DIR1-EYFP fusion band (7 or $15+26 \mathrm{kDa}$ EYFP) of 33 or $41 \mathrm{kDa}$ was not detected suggesting that EYFP was cleaved from the DIR1 protein. Although it was not possible to track DIR1 using the EYFP tag, this assay provided data that corroborates the idea that DIR1 moves to distant tissues during SAR. However, it was not possible to distinguish DIR1 from DIR1-like as the DIR1-EYFP fusion was not detected in the protein gel blot analysis.

\section{AGROBACTERIUM-MEDIATED TRANSIENT EXPRESSION OF DIR1-LIKE RESCUES THE dir1-1 SAR DEFECT}

DIR1-like's involvement in SAR was investigated by comparing DIR1-EYFP and DIR1-like in dir1-1 Agro-SAR rescue assays. Since DIR1-GUS and DIR1-EYFP fusions could not be detected in SAR-induced petiole exudates (Figures 2, 5), we chose to ectopically express DIR1-like without a reporter. Additionally, the npr1-2 SAR mutant was included in this assay as a negative control for the SAR response and also to determine if NPR1 acts downstream of DIR1 in the SAR pathway. Agrobacterium encoding DIR1-like was inoculated into dir1-1 or npr1-2 plants followed by the SAR assay 4 days later. Pst levels were reduced 4-fold in SAR-induced compared to mock-inoculated dir1-1 transiently expressing native (signal sequence-containing) DIR1-like (Figure 5C). Thus, ectopic expression of DIR1-like in one leaf of the dir1-1 mutant compensated for the dir1-1 SAR defect. However, expression of DIR1-like (Figure 5C) or DIR1-EYFP (Figure 7A) in npr1-2 did not rescue the npr1-2 SAR-defect suggesting that DIR1 and DIR1-like act upstream of NPR1 in the SAR pathway. Interestingly, SAR-induced exudates collected from dir1-1 plants expressing DIR1-like displayed a DIR1-antibody signal in protein gel blot experiments (Figure 5D), suggesting that similar to DIR1, DIR1-like moves down the petiole during SAR induction.

\section{DIR1-ANTIBODY SIGNALS ARE DETECTED IN PETIOLE EXUDATES OF DISTANT TISSUES USING THE AGRO-SAR ASSAY}

If DIR1 and DIR1-like are long distance signals during SAR, then these proteins should move not only down the petioles of induced leaves, but from these petioles to distant leaves to initiate the establishment/priming stage of SAR. This hypothesis was tested by performing Agro-SAR assays with 35S:DIR1EYFP or 35S:DIR1-like and collecting exudates starting at 24 hpi until 46 hpi from distant npr1-2 or dir1-1 leaves. The amount of DIR1 in whole leaf extracts collected from induced (Maldonado et al., 2002) and distant leaves (Figure S12) was undetectable by protein gel blot analysis. Therefore, distant leaf exudates were collected and concentrated to observe DIR1 and DIR1-like movement to distant tissues. Expression of DIR1EYFP in dir1-1 followed by SAR induction elicited a robust (>10-fold) SAR response compared to mock-inoculated plants (Figure 7A). A less robust, but statistically significant (student's $t$-test) 4-fold reduction in Pst levels was observed in SAR-induced compared to mock-inoculated plants expressing DIR1-like, and as expected, expression of DIR1-EYFP did not rescue the SAR defect in npr1-2 (Figure 7A). Exudates collected from leaves that were first inoculated with either Agrobacterium containing 35S:DIR1-EYFP, 35S:DIR1-like or 35S:EYFP followed by mockinoculation, contained no DIR1-antibody signal (Figures 6B, 7B). DIR1-antibody signals appeared to be more abundant in dir1-1 expressing DIR1-EYFP compared to DIR1-like in both induced and distant leaf petiole exudates (Figure 7B). In experiments comparing DIR1-EYFP and EYFP transient expression, DIR1 antibody signals in induced leaf exudates were similar (Figures 6B, S9), whereas DIR1-sized bands were observed only at the later timepoint $(24-48 \mathrm{hpi})$ in distant leaf exudates of plants expressing EYFP (Figure 6C). Since the DIR1 


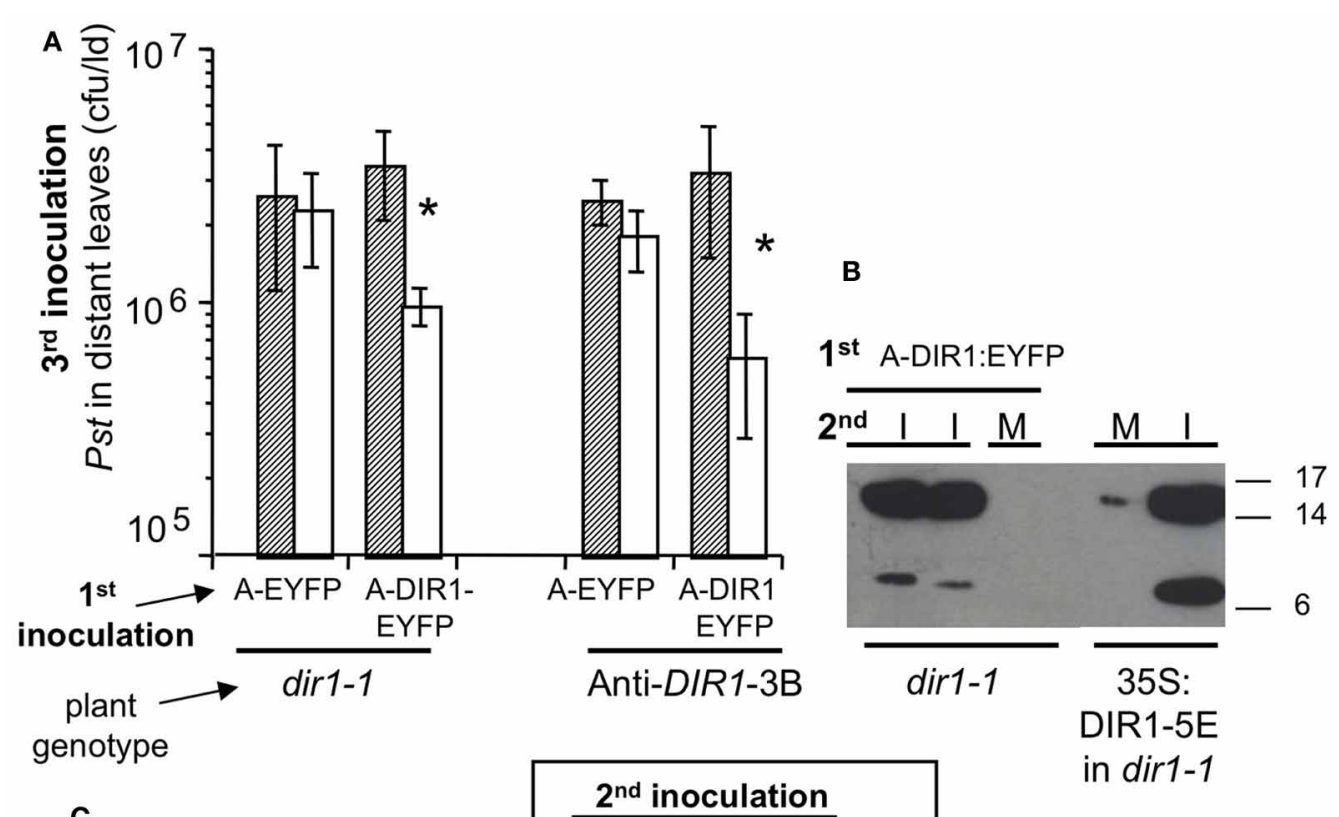

C

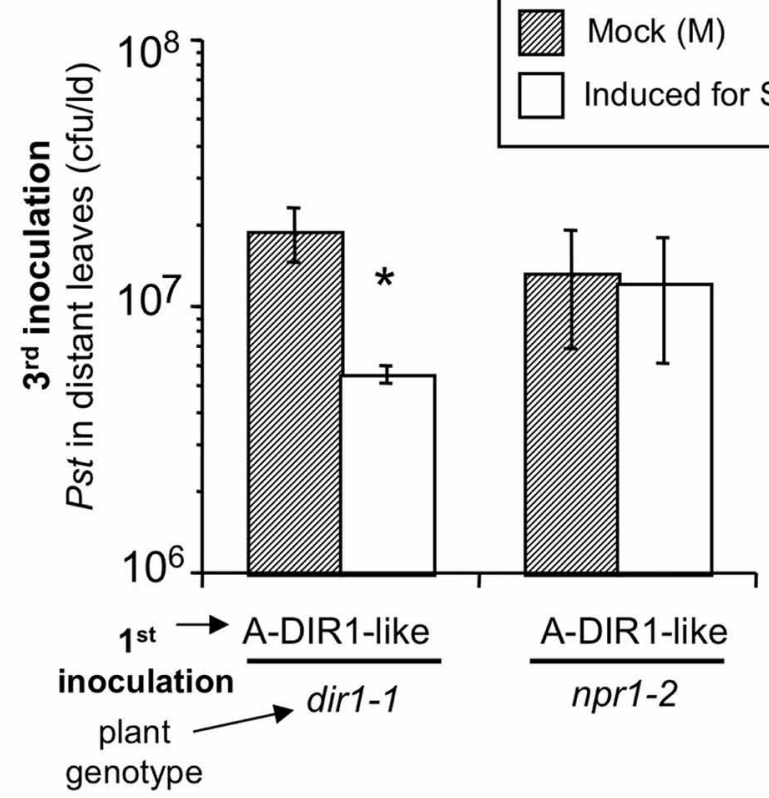

D

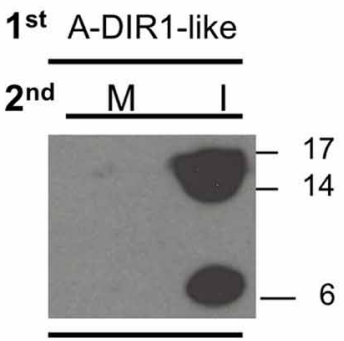

$\operatorname{dir} 1-1$
FIGURE 5 | Transient expression of DIR1 and DIR1-like in one leaf rescues the SAR defect in dir1-1. (A) dir1-1 and 35S:antisenseDIR1-3B

(Anti-DIR1-3B) plants were subjected to the Agro-SAR assay. 1st inoculation in 2 leaves with either Agrobacterium (Agro) containing EYFP or DIR1-EYFP, then a 2nd inoculation 4 days later in the same leaves with either $10 \mathrm{mM}$ $\mathrm{MgCl}_{2}$ (Mock) or $10^{6} \mathrm{cfu} \mathrm{ml}^{-1}$ Pst (avrRpt2) (Induced for SAR). Two days later, one set of plants received a 3 rd inoculation with virulent Pst $\left(10^{5} \mathrm{cfu} \mathrm{ml}^{-1}\right)$ in distant leaves and Pst levels were measured 3 dpi. Asterisks (*) denote a significant difference (student's $t$-test) in Pst levels between mock-inoculated and SAR-induced plants. (B) Petiole exudates were collected (20-44 hpi) from another set of plants that were inoculated 1st with Agro DIR1-EYFP and 2nd with either $10 \mathrm{mM} \mathrm{MgCl}_{2}$ (M- mock) or Pst (avrRpt2) (l-induced for SAR). These exudates were lyophilized and subjected to protein gel blot analysis with the DIR1 antibody. Exudates from SAR-induced 35S:DIR1-5E/dir1-1 were used as a positive control. (C) dir1-1 and npr1-2 were subjected to the Agro-SAR assay as in (A) using Agro containing DIR1-like. (D) Petiole exudates were collected from dir1-1 plants that were inoculated 1st with Agro DIR1-like, then a 2nd inoculation with mock (M) or SAR-induced (I). Protein molecular weight markers are indicated (17, 14, $6 \mathrm{kDa})$. (A-D) were repeated two additional times with similar results. antibody recognizes DIR1-like (Figure S6) and DIR1-like is expressed in dir1-1 (Figure 3), we reason that the DIR1 antibody signal in dirl-1 plants transiently expressing EYFP is due to endogenous DIR1-like. Taken together, the induced and distant leaf exudate data supports the idea that the occasional SAR-competent phenotype observed in dir1-1 could be due to DIR1-like's reduced capacity to move to distant leaves. 


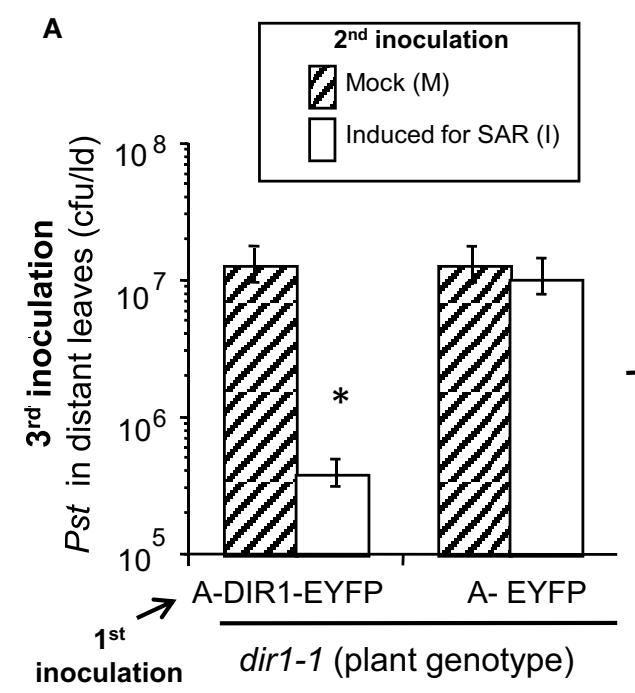

C

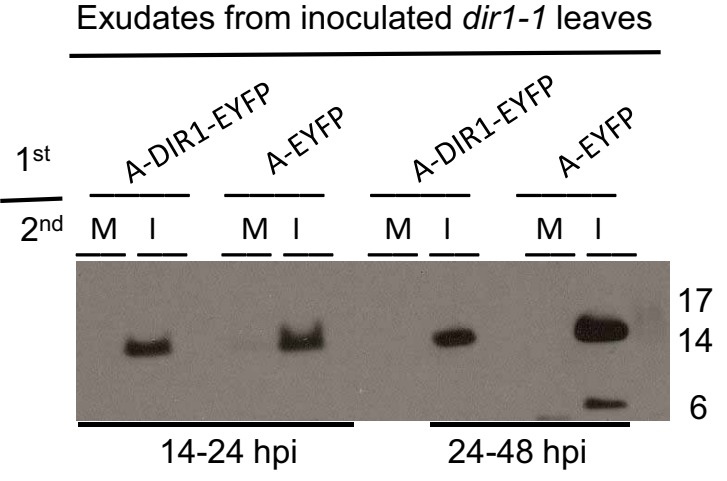

inoculation

Exudates from distant dir1-1 leaves

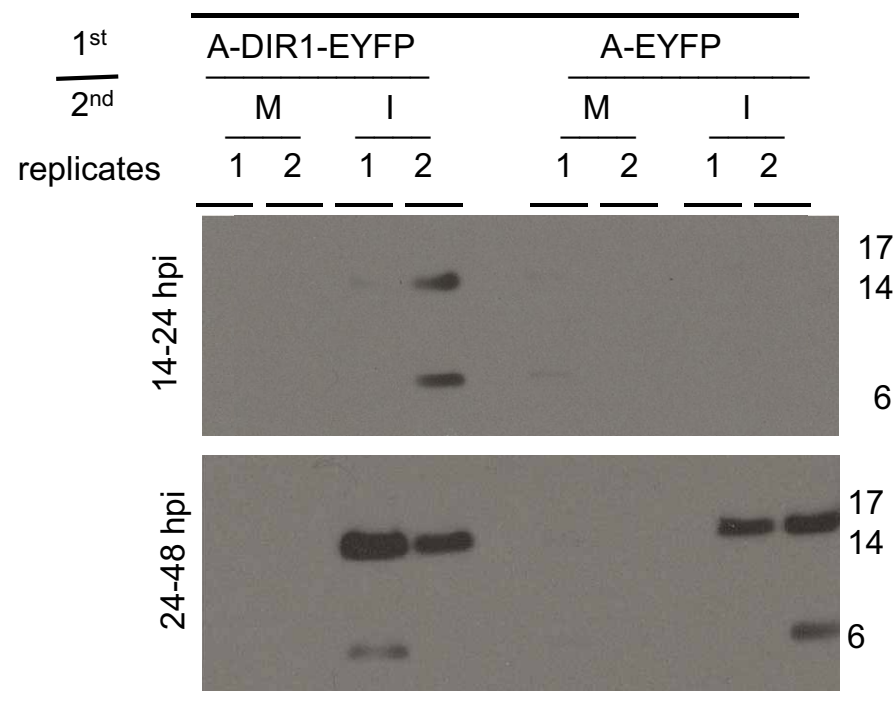

FIGURE 6 | DIR1-EYFP Agro-SAR assay and DIR1-antibody signals in distant leaf exudates. (A) The Agro-SAR assay was performed as illustrated in Figure S8. Petiole exudates were collected (14-48 hpi) from lower leaves (Inoc) which received a 1st inoculation with either Agro EYFP or DIR1-EYFP, followed by a 2nd inoculation that was either mock (M) or with SAR-inducing
Pst-avrRpt2. Exudates were also collected from distant leaves (Dis) of these same plants. Exudates from inoculated (B) or distant leaves (C) were lyophilized and subjected to protein gel blot analysis with DIR1 antibody. This experiment was repeated twice with similar results. ${ }^{*}$ denotes a significant difference (Student's $t$-test, $p<0.05$ ).

\section{MOVEMENT OF DIR1-EGFP IS OBSERVED DURING SAR USING ESTROGEN INDUCIBLE TRANSGENIC DIR1-EGFP LINES}

Our protein gel blot data using DIR1-GUS transgenics or Agrobacterium-mediated transient expression of DIR1 or DIR1like suggest that DIR1 and DIR1-like move to distant leaves during the induction stage of SAR. However, it was still not possible to differentiate DIR1 from DIR1-like in these experiments as the DIR1 antibody recognizes both proteins. To enable future microscopic studies of DIR1-EGFP movement after SAR induction, we chose to generate a stable transgenic line making use of an estrogen inducible promoter (Zuo et al., 2000). We chose this promoter because estrogen-exposed plants exhibit no developmental defects, other chemical inducers are phloem mobile, and the XVE estrogen inducible promoter provides dose-dependent and tightly regulated expression of the gene of interest (Moore et al., 2005).

A number of transgenic lines were created and molecularly characterized to confirm estrogen-specific expression of the transgenes. Before examining DIR1-EGFP translocation from SAR-induced leaves to distant tissues, in planta mobility of $\beta$-estradiol, the inducer of the XVE promoter, was examined to confirm that it is not mobile. RT-PCR was performed on 
A

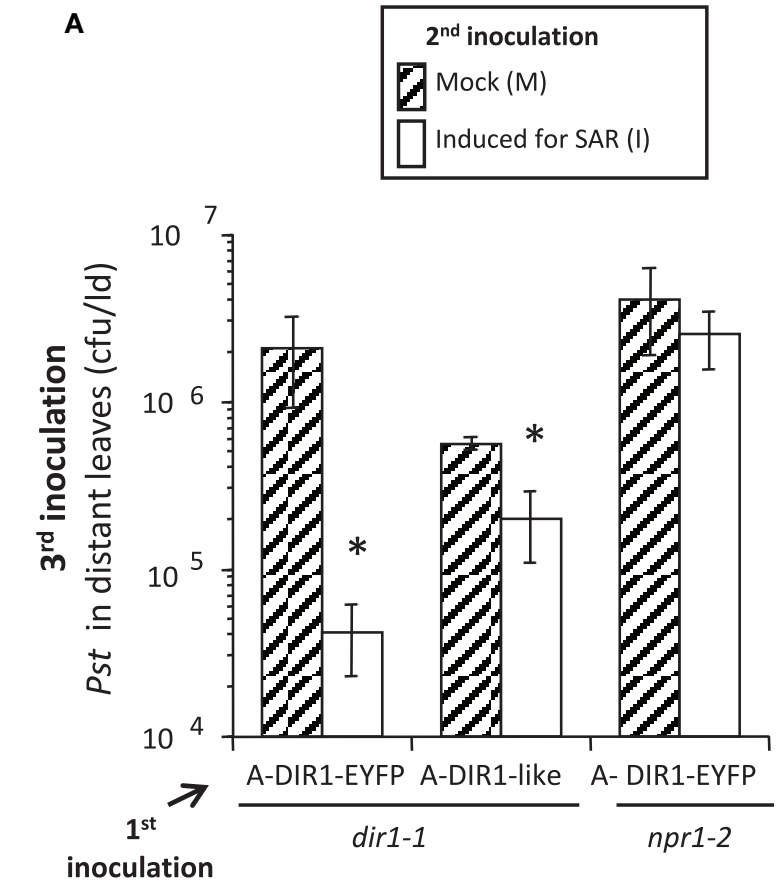

FIGURE 7 | DIR1-like Agro-SAR assay and DIR1-antibody signals in distant leaf petiole exudates. (A) The Agro-SAR assay was performed as in Figure S8. (B) Petiole exudates were collected (20-46 hpi) from mock-inoculated (M) or SAR-induced (I) lower leaves (Inoc) and from distant leaves (Dis). Exudates were lyophilized and subjected to protein gel

\section{B}

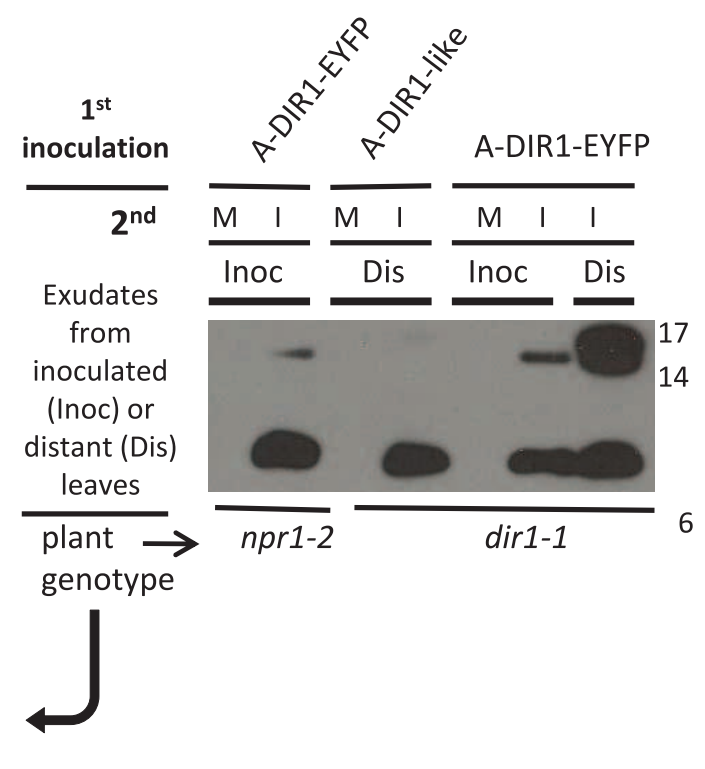

blot analysis with DIR1 antibody. Exudates from mock-inoculated distant leaves expressing DIR1-EYFP were analyzed separately (DIR1 antibody signal not observed). Protein molecular weight markers are indicated $(17,14,6 \mathrm{kDa})$. This experiment was repeated twice with similar results. *denotes a significant difference (Student's t-test, $p<0.05$ ).

estrogen-treated lower leaves as well as untreated distant leaves at various time points after estrogen treatment. DIR1-EGFP transcripts increased in a time-dependent manner in estrogen-treated leaves and were not detected in distant leaves, indicating that estrogen was not traveling systemically and expression of the transgene was restricted to locally treated leaves (Figure S10A). DIR1-like transcript levels were also examined in distant leaves to ensure that DIR1 antibody signals in distant leaves were not due to up-regulation of DIR1-like during SAR induction. Up-regulation of DIR1-like transcripts was not observed in distant leaves after SAR induction and similar to DIR1 (Figure 3), DIR1-like expression was reduced in SAR-induced leaves compared to untreated leaves (0 hpi) (Figure S10B).

Expression of DIR1-EGFP was monitored by protein gel blot analysis at various times after estrogen application and SAR induction. A DIR1-EGFP fusion of $\sim 40 \mathrm{kDa}$, as well as the 7 and $15 \mathrm{kDa}$ DIR1 monomer and dimer-sized bands were observed in leaf extracts using both DIR1 and GFP antibodies (Figure S11). Since DIR1-EGFP and DIR1 were detected in protein gel blots using whole leaf extracts this indicates that the estrogen lines express more DIR1 fusion protein compared to transient expression of DIR1-EYFP by Agrobacterium. Two lines, XVE:DIR1EGFP-2-3/dir1-1 and XVE:DIR1-EGFP-3-5/dir1-1 were analyzed in 4 independent estrogen-SAR experiments. DIR1-EGFP expression was induced in two lower leaves by estrogen infiltration, followed 14-24h later by a second inoculation to mock- or
SAR-induce the same leaves. Some plants received a third inoculation in distant leaves with virulent Pst to assay for SAR, other plants were used to examine DIR1-EGFP levels in inoculated and distant leaf petiole exudates. When treated with estrogen, both XVE:DIR1-EGFP/dir1-1 lines displayed a robust SAR response as demonstrated by the 20-fold reduction in Pst levels between mock- and SAR-induced plants, while the XVE:EGFP/dir1-1 control line did not (Figure 8). Estrogen-specific expression of DIR1-EGFP in the induced leaf rescues the SAR deficiency in dir1-1.

To determine if the DIR1-EGFP fusion is stable and detectable, exudates were concentrated and subjected to protein gel blot analysis using DIR1 and GFP antibodies. Similar to previous gel blots a DIR1 signal was not observed in mock-induced exudates (Figure 9). The DIR1 antibody detected DIR1 monomer$(\sim 7 \mathrm{kDa})$ and dimer-sized $(\sim 15 \mathrm{kDa})$ bands, as well as $\sim 40$ (DIR1-EGFP + DIR1) and $\sim 66$ (DIR1-EGFP dimer) kDa bands in exudates collected from estrogen-infiltrated/SAR-induced leaves. A duplicate blot was probed with a GFP antibody and 26 (EGFP alone), 40 and $66 \mathrm{kDa}$ bands were detected in exudates collected from estrogen-infiltrated/SAR induced leaves (Figure 8). Distant leaf exudates collected from estrogen/SAR-induced plants contained DIR1 monomer- and dimer-sized bands and a faint $40 \mathrm{kDa}$ band (DIR1-EGFP + DIR1). These data indicate that DIR1-EGFP fusion proteins of 40 and $66 \mathrm{kDa}$ can be detected using both the DIR1 and GFP antibodies in exudates collected 
$1^{\text {st }}$ - estrogen, $2^{\text {nd }}$ - mock-induced $1^{\text {st }}$ - estrogen, $2^{\text {nd }}$ - SAR-induced

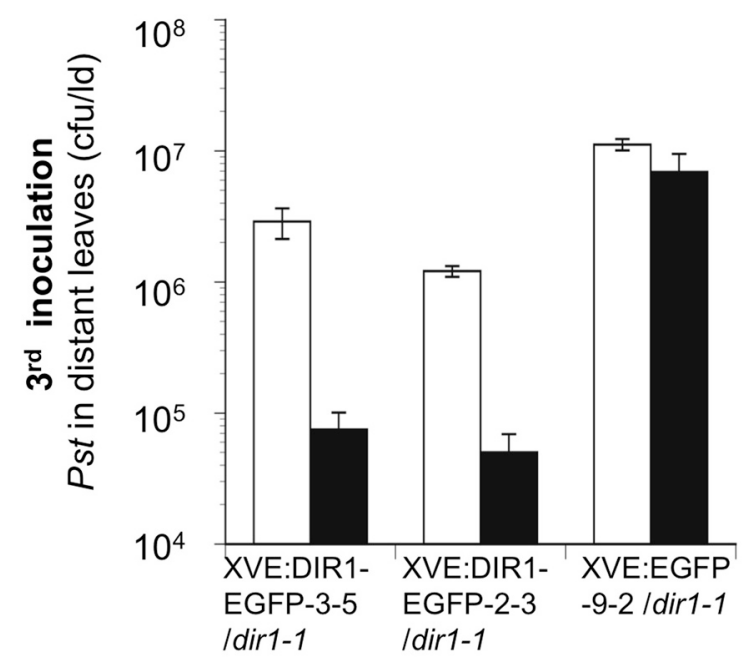

FIGURE 8 | SAR Assays using estrogen-inducible lines. EGFP and DIR1-EGFP expression was induced in XVE:DIR1-EGFP/dir1-1 I(3-5 and 2-3) and XVE:EGFP-9-2/dir1-1 by infiltrating two lower leaves with estrogen, followed $14-24 \mathrm{~h}$ later by a second inoculation to mock- or SAR-induce (Pst-avrRpt2) the same leaves. A third inoculation in distant leaves with virulent Pst was used to assay for SAR. This experiment was repeated three additional times with similar results.

from induced leaves, whereas estrogen/SAR-induced distant petiole exudates contained a faint $40 \mathrm{kDa}$ band plus abundant DIR1 monomer and dimer-sized bands. The XVE:DIR1-EGFP/dir1-1 lines make it possible to conclude that DIR1-EGFP proteins are moving from the induced leaf down the petiole to distant leaf petioles during the induction and long distance signal movement stages of SAR.

\section{USING THE SAR INDEX TO COMPARE AGRO-SAR AND ESTROGEN-SAR ASSAYS}

The outcome of a plant-pathogen interaction is dependent on the genotypes of the plant and microbe, with environmental conditions comprising the third side of the "disease triangle" (Agrios, 2005). In our experience SAR is highly affected by external environmental conditions even in growth chambers, therefore we perform SAR experiments over a number of years to obtain a more complete picture of the SAR response in the ecotypes or mutants we study. This led us to observe the infrequent (6.7\%) and partially SAR-competent phenotype of dirl-1 and led us to investigate DIR1-like which required that we perform numerous SAR assays over the last 5 years $\left({ }^{\prime} 07-^{\prime} 11\right)$ using two approaches (transient DIR1 and DIR1-like expression and stable inducible DIR1 expression). To objectively compare 5 years of data and two experimental types, a method to quantify the SAR response was needed. First, a SAR response scale $(0$ to ++++$)$ was created (Table $\mathrm{S} 1$ ) and the $\mathrm{SAR}^{+}$responses per year or across all years were calculated. This provided an overall view of SAR competence

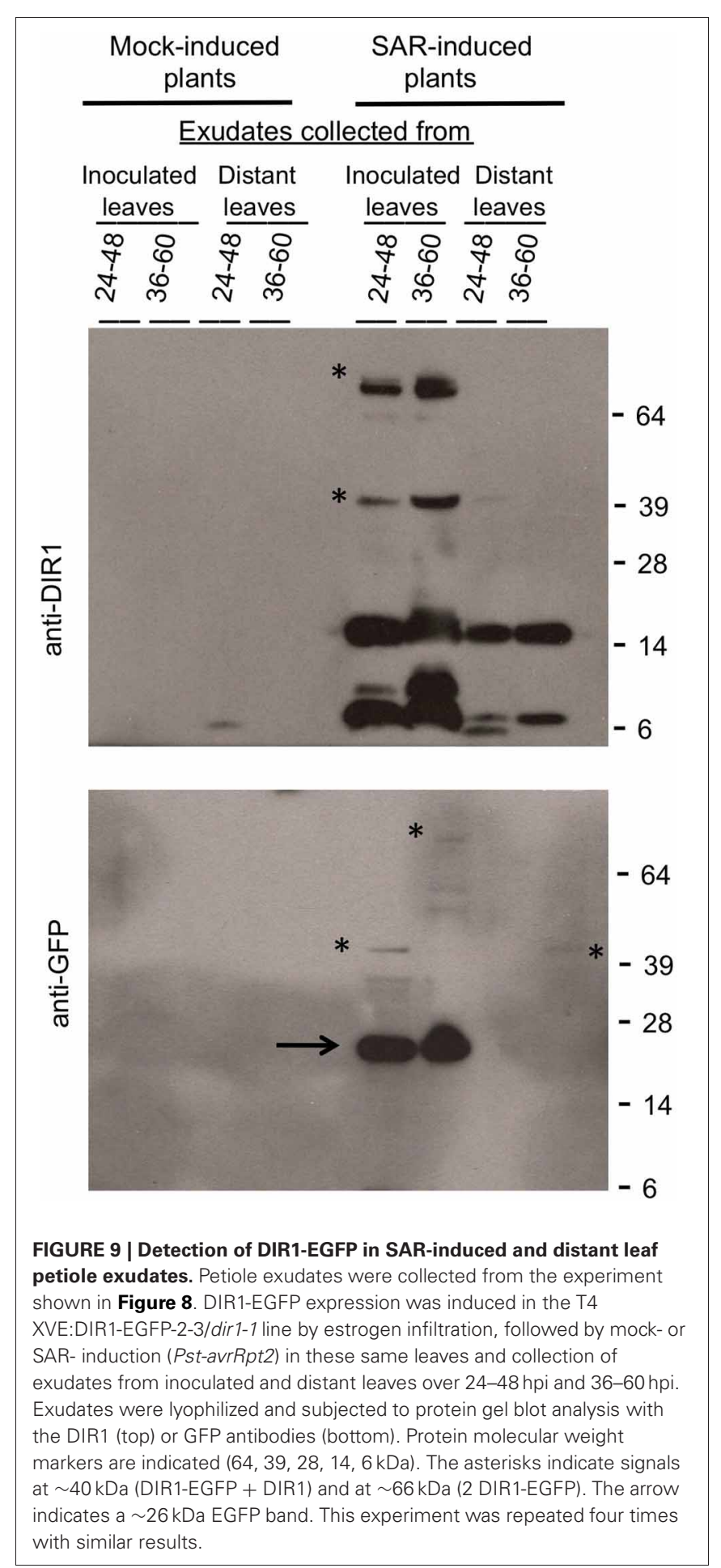

as all SAR responses from modest $(+)$ to robust $(++++)$ were considered to be $\mathrm{SAR}^{+}$such that transient expression of DIR1like and DIR1-EYFP in dir1-1 had similar SAR ${ }^{+}$responses over all years (71 and 75\%, respectively). Next, a SAR index was created to account for varying degrees of SAR competence and varying numbers of experiments and is defined as the sum of (SAR response $\mathrm{x}$ \# experiments)/total \# experiments for each year or 
average for all years (Table S1). Stable expression of DIR1-EGFP and EGFP (endogenous DIR1-like) from the estrogen-inducible XVE promoter in the dir 1-1 mutant had SAR indices of 4 and 0 , respectively, compared to 1.5 for DIR1-EYFP, 1.0 for DIR1-like and 0.4 for endogenous DIR1-like (EYFP control) in Agro-SAR assays, indicating that the XVE:DIR1-EGFP/dir1-1 stably transformed line is highly SAR-competent. SAR index values were also compared to examine the contribution of endogenous DIR1like (EYFP control) to DIR1-like expressed transiently from the $35 \mathrm{~S}$ promoter, such that dir1-1 expressing endogenous DIR1-like had a lower SAR index of 0.4 , compared to 1.0 for transiently expressed DIR1-like. Although DIR1-like expressed transiently by Agrobacterium rescued the dir1-1 defect with a SAR index of 1.0, transiently expressed DIR1-EYFP had a higher SAR index of 1.5. Therefore, the SAR index is a valuable tool that provides a quantitative way to compare numerous assays performed over many years and provides support for the idea that DIR1-like (expressed from its endogenous promoter or transiently from the 35 S promoter) contributes less effectively to SAR compared to DIR1.

\section{DISCUSSION}

The occasionally SAR-competent phenotype of dir1-1 led us to investigate the role of DIR1-like, a highly similar gene adjacent to DIR1 on chromosome 5. Our phylogenetic analysis provides evidence that DIR1 and DIR1-like are paralogous genes and that this duplication occurred before the divergence of A. thaliana and A. lyrata. We developed an Agrobacterium-mediated transient transformation/SAR assay to examine DIR1 movement during SAR and to examine DIR1-like's participation in SAR. It was possible to rescue the SAR defect in dir1-1 by transiently expressing DIR1 in one leaf followed by SAR induction in the same leaf, demonstrating the utility of the Agro-SAR assay and providing evidence that transient expression of DIR1 in a single induced leaf is sufficient to rescue the SAR defect in dir1-1. Given that DIR1-like is expressed at wild-type levels in dir11 and dir1-1 is rarely SAR-competent, it was surprising that Agrobacterium-mediated transient expression of DIR1-like rescued the SAR-defect in dir1-1 in 3 of 4 experiments. Because Agrobacterium-mediated transient expression does not support high levels of ectopic expression in Arabidopsis (Tsuda et al., 2012 and this work), we propose that during the Agro-SAR assay, sufficient DIR1-like expression occurs in leaf cells particularly important for SAR induction resulting in rescue of the dir1-1 SAR defect.

Transient expression of DIR1 or DIR1-like did not rescue the SAR defect in the npr1-2 SAR mutant, supporting the idea that NPR1 acts downstream of DIR1 in distant leaves during SAR [discussed in Champigny and Cameron (2009)]. Moreover, a DIR1-sized band was detected in npr1-2 exudates collected from leaves induced for SAR suggesting that DIR1 long distance movement does not require the presence of NPR1.

DIR1 protein was typically undetectable in leaf extracts obtained from wild-type and DIR1 promoter transgenic lines and could be detected only in concentrated petiole exudates or IWFs suggesting that endogenous DIR1 levels are low in Arabidopsis (Champigny et al., 2011 and this work). We also demonstrated that expression of DIR1 and DIR1-like is further reduced during SAR induction (Champigny et al., 2011, this work), reinforcing the idea that only a small amount of DIR1 is required to manifest the SAR response. Using a proteomicsbased approach, we attempted to identify DIR1 and/or DIR1-like in SAR-induced petiole exudates. However, neither DIR1 nor DIR1-like protein could be detected by LC-MS/MS (liquid chromatography followed by tandem mass spectrometry) even in pooled, concentrated exudates collected from 35S:DIR1 overexpression lines. DIR1 moving into petiole exudates collected from wild-type plants and our transgenic lines can only be detected using highly sensitive chemiluminescent protein gel blot analysis (Pierce-pico to femtogram detection range). Based on all of these observations, the amount of DIR1 contributing to long distance signaling in wild-type plants appears to be very low.

Agrobacterium-mediated transient expression in Arabidopsis is rarely reported in the literature (Nimchuk et al., 2000; Wroblewski et al., 2005; Tsuda et al., 2012) as insufficient expression of the gene of interest is observed, probably due to an effective basal/PAMP-triggered immune response initiated by Arabidopsis to Agrobacterium (Zipfel et al., 2006). Nevertheless, transient expression of DIR1 and DIR1-like in single leaves using this method was sufficient to rescue the SAR defect in dir1-1, likely due to the fact that little DIR1 is necessary for SAR as discussed above. The Agro-SAR assay offers some advantages over transgenic approaches, chiefly the time required to generate and characterize transgenic lines, and can be employed to test the role of newly discovered genes in the SAR response. For example, our experiments establish that expression of DIR1 is required only within SAR-induced leaves. The Agro-SAR assay could be used to test the spatial and temporal requirements for other SAR proteins during the induction or manifestation stages of SAR.

Unexpected results were obtained when protein blots were performed on petiole exudates and IWFs collected from plants expressing DIR1-GUS or DIR1-EYFP. IWFs as well as petiole exudates collected from these plants consistently exhibited a $\sim 15$ and sometimes $\sim 7 \mathrm{kDa}$ signal, but not the 75 or $33 \mathrm{kDa}$ signals expected of DIR1-GUS or DIR1-EYFP fusion proteins, respectively. We considered but ruled out the possibility that the fusion proteins were not expressed because plants expressing DIR1fusion proteins were capable of rescuing the dir1-1 SAR defect. Secondly, the expected $75 \mathrm{kDa}$ DIR1-GUS fusion was detected in whole leaves from DIR1-GUS transgenics using both DIR1 and GUS antibodies. As expected, transgenics expressing GUS fusions with either full-length DIR1 or DIR1 lacking its signal sequence exhibited intracellular GUS activity in whole leaves and leaf cross-sections. Additionally, IWFs isolated from DIR1-GUS transgenics contained an abundant $\sim 15 \mathrm{kDa}$ DIR1 signal and GUS enzyme activity, indicating that DIR1 and GUS coexist as active proteins within the apoplast of these plants. Our results suggest that GUS and EYFP are cleaved from DIR1 such that little DIR1 fusion protein is present in the apoplast or phloem sapenriched petiole exudates. Fortunately, it was possible to detect DIR1-EGFP expressed from the estrogen-inducible promoter in exudates collected from SAR-induced leaves. However, a fraction of the DIR1-EGFP fusion proteins were cleaved such that DIR1 monomer/dimer and EGFP monomer-sized bands were 
observed. In distant leaf exudates, DIR1 monomer- $(7 \mathrm{kDa})$ and dimer-sized $(15 \mathrm{kDa})$ bands were abundantly present, while only a modest signal of DIR1-EGFP $(\sim 40 \mathrm{kDa})$ was detected indicating that many fusion molecules were cleaved during movement to distant leaves. Using both the DIR1 and GFP antibodies, $\sim 40$ and $\sim 66 \mathrm{kDa}$ bands were detected in exudates from SAR-induced leaves, however the GFP antibody signal was less intense than the DIR1 antibody signal. Although caution must be used when comparing band intensities of independent blots using different antibodies, an alternative explanation for the $\sim 40$ and $\sim 66 \mathrm{kDa}$ DIR1 antibody bands, is that DIR1 monomers associated with other proteins in a DTT-resistant manner, given that $200 \mathrm{mM}$ DTT was added to the exudates before electrophoresis and blotting. Either explanation (DIR1 dimers or DIR1-protein complexes) fits with the appearance of trypsin-sensitive high molecular weight fractions in dehydroabietinal-elicited SAR observed by Chaturvedi et al. (2012). Nevertheless, DIR1-EGFP-sized bands ( 40 and $\sim 66 \mathrm{kDa})$ were detected with the GFP antibody in exudates collected from both SAR-induced and distant leaves, providing evidence that DIR1-EGFP moved from SAR-induced to distant leaves.

Cleavage of peptide moieties from fusion proteins expressed in plants is infrequently documented in the literature. In one report (daSilva et al., 2006), it was observed that a translational fusion between GFP and a vacuolar protein was mislocated to the apoplast and resulted in cleavage of GFP in transgenic tobacco. In addition, expression of an HA- and GFP-tagged Cf-9 transmembrane resistance receptor, in yeast, Arabidopsis and tobacco cells resulted in appropriate accumulation of the fusion protein within the vacuole of yeast cells but inappropriate secretion to the apoplast followed by cleavage of the HA and GFP tags in both plants (Benghezal et al., 2000). It is interesting to note that in this study, unexpected cleavage of DIR1 fusion proteins appears to occur during movement of DIR1 to distant leaves via the phloem and in the apoplast (IWFs), which is consistent with numerous observations that the apoplast is enriched in proteases (Misas-Villamil and Al van der Hoorn, 2008).

The movement of native DIR1 in SAR-induced Arabidopsis was not addressed in our previous reports (Maldonado et al., 2002; Champigny et al., 2011) or in Chanda et al. (2011) although numerous reviews (Durrant and Dong, 2004; Parker, 2009; Dempsey and Klessig, 2012) present models in which DIR1 translocates to distant tissues during SAR. Because petiole exudates collected from dirl-1 plants did not induce SAR marker (PR1) expression in distant leaves, the data presented in Maldonado et al. (2002) supports a role for DIR1 in the production or long-distance translocation, of a SAR signal. Chanda et al. (2011) observed the accumulation of ectopically expressed Arabidopsis DIR1-EGFP in N. benthamiana distant leaves after exogenous G3P treatment. Therefore, the data presented here fills a gap in the SAR model by providing compelling evidence for the long-distance translocation of DIR1 during biologically-induced SAR in Arabidopsis.

DIR1 antibody signals of both $\sim 7$ and $15 \mathrm{kDa}$ were detected in protein gel blot analysis of petiole exudates and IWFs collected from wild type plants suggesting that DIR1 is present in monomeric form and also exists as either a homodimer as is the case for the peach Prup3 LTP (Pasquato et al., 2005) or as a heterodimer with another LTP, as is the case for the barley LTP1-LTP2 complex (Gorjanović et al., 2005; Gorjanović, 2007). The LTP1-LTP2 dimer was disrupted in the presence of reducing agents suggesting that disulfide bonds hold the monomers together (Gorjanović, 2007). Incubation of DIR1 exudates in elevated concentrations of a reducing agent $(200 \mathrm{mM})$ resulted in the appearance of the $\sim 7 \mathrm{kDa}$ band. These experiments suggest that DIR1 participates in dimers in which the monomers are held together by DTT-resistant interactions. Although we do not preclude that DIR1 could participate in a heterodimer with DIR1like or another protein, protein gel blots performed on petiole exudates collected from the SAR induced XVE:DIR1-EGFP lines suggest that DIR1 dimerizes with itself. In these experiments $7 \mathrm{kD}$ and $15 \mathrm{kD}$ signals were detected along with a $66 \mathrm{kDa}$ signal which is the predicted size of a homodimer comprised of two DIR1-EGFP molecules.

In our studies using wild-type Ws and DIR1pro:DIR1GUS/dir1-1 lines, faint DIR1-sized bands were detected in petiole exudates collected between 14 and $20 \mathrm{~h}$ post SAR induction, with band intensity increasing from 38 to 44 hpi suggesting that it takes the SAR signal at least $14 \mathrm{~h}$ to move down the petiole. However, leaf detachment experiments demonstrated that it takes $4 \mathrm{~h}$ in cucumber (Rasmussen et al., 1991) and 4-6 h in Arabidopsis (Truman et al., 2007; Chaturvedi et al., 2012) for the SAR signal to move out of the induced leaf. It may be that DIR1 does move out of the induced leaf between 4 and $6 \mathrm{~h}$ post SAR induction, but at levels below the detection limit of protein gel blot analysis until sufficient DIR1 accumulates in petiole exudates by $14-20 \mathrm{~h}$ post SAR-induction.

To distinguish the roles of DIR1 and DIR1-like during SAR, transgenic plants expressing 35S:antisenseDIR1-like in Ws and the dirl-1 mutant were created to generate dirl-like and dirldirl-like double mutants, respectively. Although potential dirl-like single and dirldirl-like double mutants were identified in over 50 transgenic lines (T2 generation) using qRT-PCR (data not shown), homozygous T3 plant lines with reduced DIR1-like expression were not recovered. We observed that DIR1like expression in the T3 35S:antisenseDIR1-like lines was not silenced, instead DIR1-like was expressed at wild-type levels. In addition, several T2 35S:antisenseDIR1-like/dir1-1 lines with reduced expression of DIR1-like failed to produce viable seeds suggesting that reduction of DIR1-like expression is lethal. These observations suggest that DIR1-like function may be important during seed development. Estrogen-inducible DIR1-like RNAi lines will be created to circumvent the lethality issue and further investigate DIR1-like's contribution to SAR.

Since the discovery of DIR1 and its involvement in SAR long distance signaling (Maldonado et al., 2002), a number of studies report the existence of multiple SAR mobile signals, including MeSA (Park et al., 2007; Vlot et al., 2008; Liu et al., 2010b), jasmonic acid (JA) (Truman et al., 2007), azeleic acid (AA) (Jung et al., 2009), a CDR1-derived peptide (Xia et al., 2004), plastid glycerolipids (Nandi et al., 2004; Chaturvedi et al., 2008), G3P (Chanda et al., 2011) and an abietane diterpenoid, dehydroabietinal (Chaturvedi et al., 2012). However, two studies suggest that JA (Chaturvedi et al., 2008; Attaran et al., 2009) and MeSA 
(Attaran et al., 2009) are not SAR long distance signals. It has been postulated that multiple mobile signals participate in SAR long distance signaling and that environmental conditions, developmental plant age and the particular plant-pathogen system may impact which signals are required and this may explain what appear to be contradictory results (Champigny and Cameron, 2009; Liu et al., 2010b). In this work, we provide evidence suggesting that DIR1-like occasionally contributes to SAR. This may explain the variable results observed in different labs [discussed in Dempsey and Klessig (2012)]. For example differential SAR responses are observed when plants receive different amounts of light after SAR induction in both wild type and SAR mutants including dir1-1 (Liu et al., 2011b). However, it is still possible that the partial SAR response occasionally observed in dir1-1 is not due to DIR1-like.

Using G3P infiltration assays, Chanda et al. (2011) suggest that DIR1 is required for G3P-induced resistance and investigated the effect of G3P on DIR1 movement. After infiltration of ${ }^{14} \mathrm{C}-\mathrm{G} 3 \mathrm{P}$ and recombinant DIR1 into Arabidopsis leaves, ${ }^{14} \mathrm{C}-\mathrm{G} 3 \mathrm{P}$ was detected in distant leaves. From this, Chanda et al. (2011) suggested that DIR1 is required for G3P movement during SAR. However, a high level of DIR1 protein (20 ug) was infiltrated into leaves perhaps inducing necrosis which in turn could induce G3P movement. Moreover, it is unlikely that DIR1's four disulphide bonds formed correctly during expression in the E. coli expression system used. Therefore, the role of G3P in DIR1 movement requires further investigation. Chaturvedi et al. (2008) suggest that DIR1 and plastid glycerolipids act together during long distance signaling. Moreover, DIR1 is required for AA-induced (Jung et al., 2009) and dehydroabietinal-induced resistance (Chaturvedi et al., 2012). These studies along with the DIR1 movement data presented in this work, lead us to hypothesize that DIR1 may interact with one or more of these molecules acting as a chaperone or component of a complex(s) that moves to distant leaves during SAR.

\section{MATERIALS AND METHODS PLANT GROWTH CONDITIONS}

Arabidopsis seeds from wild type (ecotype Ws-2), dir1-1, npr1-2 and all transgenic Arabidopsis lines were surface sterilized and germinated on solid Murashige and Skoog (MS) medium for 5-7 days under continuous light. Seedlings were transferred to soil (Sunshine Mix \#1), hydrated with $1 \mathrm{~g} / \mathrm{L}$ 20-20-20 fertilizer and grown for 3-4 weeks at $22^{\circ} \mathrm{C}, 9 \mathrm{~h}$ photoperiod at $150 \mu \mathrm{E} \mathrm{m}^{-2} \mathrm{~s}^{-1}$ light intensity and $65-85 \%$ relative humidity.

\section{PATHOGEN CULTURE AND INOCULATION}

Virulent (containing pVSP1) and avirulent (containing pVSP1 + avrRpt2) Pseudomonas syringae pv. tomato DC3000 strains used in this study are previously described (Whalen et al., 1991). SAR experiments at McMaster were sometimes done using the coronatine mutant Pseudomonas syringae pv maculicola ES4326 (Psm) containing avrRpt2 strain (Cui et al., 2005). No difference was found between these strains in terms of their ability to induce SAR. Bacteria were cultured overnight in King's B medium, diluted to either $10^{5}$ or $10^{6} \mathrm{cfu} \mathrm{ml}^{-1}$ in $10 \mathrm{mM} \mathrm{MgCl}_{2}$ and pressure infiltrated into the abaxial side of a leaf using a needleless $1 \mathrm{ml}$ syringe. Quantification of in planta bacterial levels was performed by dilution plating essentially as described (Cameron et al., 1999). Agrobacterium tumefaciens strain GV3101 (Agro) was cultured as described in Wroblewski et al. (2005).

\section{AGRO-SAR AND ESTROGEN-SAR ASSAYS}

Agro-SAR and estrogen-SAR assays were performed on 3.54 weeks old plants (24-28 days post germination, dpg). All SAR assays were performed between June and October as SAR assays are rarely successful during the winter and spring even in wild type Ws-2 plants. Plants were SAR-induced by inoculation of two lower leaves with avirulent Pst (avrRpt2) $\left(10^{6} \mathrm{cfu}\right.$ $\mathrm{ml}^{-1}$ ) or mock-inoculated, followed by challenge inoculation of distant leaves with $10^{5} \mathrm{cfu} \mathrm{ml}^{-1}$ virulent Pst DC3000 and in planta bacterial level determination 3 dpi. Agro-SAR experiments were conducted by transiently expressing DIR1:EYFP or DIR1-like in two lower leaves by inoculation with Agrobacterium tumefaciens GV3101 (0.4 OD 600 ) harboring 35S:DIR1-EYFP or 35S:DIR1-like binary expression vectors (Wroblewski et al., 2005). At $4 \mathrm{dpi}$, agro-inoculated leaves were then mock- or SAR-induced followed by challenge inoculation with virulent Pst in distant leaves as described above. Estrogen-SAR assays were performed by first pressure infiltrating two lower leaves of XVE:DIR1EGFP/dir1-1 or XVE:EGFP/dir1-1 lines with $50 \mu \mathrm{M} \beta$-estradiol to initiate expression of the transgene. 14-24 h following estrogen treatment, the same lower leaves were mock- or SAR-induced followed by challenge inoculation with virulent Pst in distant leaves 3 days later as described above. The first stage of SAR, induction with Pst (avrRpt2) was always performed in the morning between 9 am and noon, for all SAR assays.

\section{INTERCELLULAR WASHING FLUID, PETIOLE EXUDATE COLLECTION AND LEAF PROTEIN EXTRACTIONS}

Fully expanded leaves of 3-4 weeks old Arabidopsis plants were vacuum infiltrated with sterile distilled water for $30 \mathrm{~min}$, blotted with absorbent paper to dry the leaf surfaces, followed by IWF collection from leaves by centrifugation at $1000 \mathrm{~g}$ for $30 \mathrm{~min}$ at $4^{\circ} \mathrm{C}$ (Kus et al., 2002). Fifty leaves produced approximately 200$300 \mu \mathrm{l}$ IWF. IWFs were sampled immediately for GUS activity or frozen at $-20^{\circ} \mathrm{C}$ until protein gel blot analysis was performed.

The Arabidopsis petiole exudate method was modified from the method of King and Zeevaart (1974). Leaves were mockinoculated or induced for SAR by inoculation with Pst (avrRpt2) $\left(10^{6} \mathrm{cfu} \mathrm{ml} \mathrm{m}^{-1}\right)$. By using a lower dose $\left(10^{6} \mathrm{cfu} \mathrm{ml}^{-1}\right)$, not all cells in the leaf undergo the HR, therefore the leaf and petioles remain intact throughout the exudation process. Petioles exudates were collected at different times after induction by cutting one petiole at a time just above the stem, followed by surface sterilization for $10 \mathrm{~s}$ ( $50 \%$ ethanol, $0.0006 \%$ bleach), rinsing in sterile $1 \mathrm{mM}$ EDTA and submerging petioles in $\sim 1.5 \mathrm{ml} 1 \mathrm{mM}$ EDTA (must be done quickly to prevent sieve element clogging) and $50 \mu \mathrm{g} \mathrm{ml}^{-1}$ ampicillin (to kill any remaining surface bacteria). The sterilization step must be long enough to kill Pst clinging to leaf surfaces, but not long enough to kill the Pst in the plant intercellular spaces. The petioles of seven to ten leaves (depending on size) per microfuge tube were allowed to exude phloem sap over 2 days (early experiments) in a humid environment 
(90-100\%) on the lab bench, to produce one exudate. In later experiments, petioles were allowed to exude for less time (5 or $24 \mathrm{~h}$ ) to reduce leakage of proteins from petiole cells that occurs because of EDTA-induced tissue softening (Hepler, 2005). Petiole exudate samples $(\sim 1.5 \mathrm{ml})$ contained between 5 and $50 \mu \mathrm{g}$ total protein (Biorad Protein Assay Kit) and were stored at $-20^{\circ} \mathrm{C}$ until concentration by lyophilzation followed by protein gel blot analysis. Leaf weight could not be used to normalize exudate amounts loaded per lane as cut petioles must be immersed immediately in EDTA, allowing no time for weighing. In some experiments, exudate total protein levels were in the lower range (3-10 ug/exudate) and a DIR1 antibody signal could still be detected. Therefore, for each experiment, the same number of exudates per lane were loaded (1-4) to detect a DIR1 antibody signal.

Total protein extracts were prepared from leaf tissue by grinding flash-frozen leaves in liquid nitrogen to a fine powder and extracting with $50 \mathrm{mM}$ Tris $\mathrm{pH} 7.5,1 \mathrm{mM}$ EDTA, $100 \mathrm{mM} \mathrm{NaCl}, 1 \%$ NP-40, 0.1\% SDS, 0.1\% Triton X-100, 0.7\% 2mercaptoethanol, $1 \mathrm{mM}$ PMSF. Protein concentration was determined by Bradford assay (Biorad Protein Assay Kit) and 30-50 $\mu \mathrm{g}$ was loaded per lane.

\section{DIR1 TRANSCRIPT ABUNDANCE DETERMINATION USING RT-PCR}

Total RNA was isolated from frozen leaf samples from various Arabidopsis transgenic lines, 35S:DIR1-5E/dir1-1, DIR1pro:DIR1:GUS-29/dir1-1, 35Spro:antisenseDIR1-3B, and in addition to dir1-1 and wild-type Ws plants, using Trizol reagent (Invitrogen, Carlsbad, CA). Two micrograms of the total RNA was treated with RNase-free DNase I (Invitrogen, life technologies) as per the manufacturer's instructions. RTPCR of DIR1 expression with DNase I-treated RNA (500 ng) was performed using One-Step RT-PCR kit (Qiagen) and a primer pair (5'-ATGGCGACGAAGAAAGCAGC- $3^{\prime}$ and $5^{\prime}$ AACAATTGGGGCGTTGGCTAG- $3^{\prime}$ ) designed from coding sequence. All RT-PCR reactions were performed with $2 \mu \mathrm{l}$ of RT-PCR enzyme mix, the buffer provided by the supplier, $0.2 \mathrm{mM}$ dNTPs, and a primer pair $(0.6 \mu \mathrm{M}$ each $)$ in a final volume of $25 \mu \mathrm{l}$. The RT-PCR conditions were as follows: $50^{\circ} \mathrm{C}$ for $30 \mathrm{~min}$ and $95^{\circ} \mathrm{C}$ for $15 \mathrm{~min}$ for RT steps followed by 28 PCR cycle of $94^{\circ} \mathrm{C}$ for $30 \mathrm{~s}, 60^{\circ} \mathrm{C}$ for $45 \mathrm{~s}$, and $72^{\circ} \mathrm{C}$ for $1 \mathrm{~min}$, with a final polymerization step at $72^{\circ} \mathrm{C}$ for $10 \mathrm{~min}$. Actin 1 (At2g37620) was used as control for RNA levels in each sample using primers Actin1F (5'-GGCGATGAAGCTCAATCCAAACG$\left.3^{\prime}\right)$ and Actin1R (5'-GGTCACGACCAGCAAGATCAAGACG-3'). DIR1-EYFP expression was monitored using RT-PCR (same conditions as above) in leaves inoculated with Agrobacterium (35S: DIR1-EYFP) at 1, 2, 3, and 4 dpi using forward DYfusion5p (5'-GGTGTTGATCCTGAACTCGC-3') and reverse primers, DYfusion $3 p \quad\left(5^{\prime}\right.$-AACTTCAGGGTCAGCTTGCC- $\left.3^{\prime}\right)$. These primers produce a PCR product that spans the DIR1 EYFP fusion.

\section{QUANTITATIVE RT-PCR (ABSOLUTE QUANTIFICATION METHOD-FOBERT LAB)}

Flash frozen leaf tissue $(0.1-0.2 \mathrm{~g})$ was ground to a fine powder in liquid nitrogen and total RNA was extracted according to the manufacturer's instructions with a Plant Mini RNA isolation kit (Qiagen). RNA was treated with DNAse I (Invitrogen) to remove contaminating genomic DNA then $2 \mu \mathrm{g}$ treated RNA was reverse transcribed to cDNA with Superscript II (Invitrogen) polymerase. The cDNA was diluted 10-fold with water and subject to kinetic PCR amplification on a MX3000P spectrofluorometric thermal cycler (Stratagene). Total volume reactions were of $12.5 \mu \mathrm{L}$ and contained $5 \mathrm{ng}$ cDNA and 1 X SYBR Green ${ }^{\circledR}$ (Quantitech, Qiagen). The annealing and elongation step of the amplification cycle was performed at $66^{\circ} \mathrm{C}$ and 40 cycles were used. Primers used to amplify DIR 1 transcript were: Forward primer $5^{\prime}$ GATCGTGATAATGGCTATGTTGGTCGATACATC, reverse primer 5'-GCGTTGGCTAGACCACACTGTTTGGGGAGAGC. Primers used to amplify DIR1-like (At5g48490) transcript were: forward primer 5'-AATGGTGATGGCTAGTTTAGTCGTT GAGAGG, reverse primer 5'-TAAACAAACAAAGGAAAA CACCATAATGC. Specificity of PCR primers was verified by sequencing of representative PCR products. The number of transcript molecules was calculated using the "absolute quantification via Ct" method (Rutledge and Stewart, 2008). Gene expression was standardized to expression levels of UBQ5, whose transcripts were monitored with forward primer $5^{\prime}$ AGCTTACAAAATTCCCAAATAGAAATGCAG and reverse primer 5'-ACCTACGTTTACCAGAAAGAAGGAGTTGAA.

\section{QUANTITATIVE RT-PCR (ABSOLUTE QUANTITATION METHOD-CAMERON LAB)}

Total RNA was extracted from Arabidopsis leaf tissue using Trizol (sigma) method followed by DNA removal using Turbo DNase Free (Ambion). First strand cDNA synthesis was performed using $2 \mu \mathrm{g}$ of total RNA as template which was reverse transcribed into cDNA by MMLV (Life Science Technologies) using manufacturer instructions and diluted 3 fold in water before use. qRT-PCR was performed in a $10 \mathrm{ul}$ reaction consisting of 2 ul of diluted cDNA, LuminoCT SYBR Green qPCR ready mix (Sigma) and 200 or $400 \mathrm{nM}$ of primer. The mixture was loaded into low profile optical 96-well plates. qRT-PCR was performed in the Bio-Rad CFX96 touch ${ }^{\mathrm{TM}}$ Real-Time PCR Detection System and analyzed using BioRad CFX manager 2.0 software. Gene specific primers were validated for specificity and efficiency using an 8 point standard curve and purified products were Sanger sequenced to confirm identity. Primer secondary structure was evaluated using mfold $\downarrow$ (http://mfold.rna.albany.edu/). Primers used were $5^{\prime}$ TCGTGATAATGGCTATGTTGGTC $3^{\prime}$ and $5^{\prime}$ ACTGTTTGGGGAGAGCAGAAG $3^{\prime}$ for DIR1, $5^{\prime}$ AATAAAGAGGATAAAATGACAAGC $3^{\prime}$ and $5^{\prime}$ CTGGTAAGCA TTCATTCAACTC $3^{\prime}$ for DIR1-like, 5' TGTCCGCAAATC CCTAAAAG $3^{\prime}$ and 5' CCAGGGAGCTTCAAGAACAG $3^{\prime}$ for 5FCL. Genevestigator was used to choose the 5FCL reference gene based on the transcript stability and a similar expression range to our genes of interest. All samples were analyzed in three biological and technical replicates. A no template control as well as a no reverse transcriptase control were run simultaneously with the samples. For absolute quantification, standard curves (\# of template copies vs. $C_{T}$ plots) generated 
from known quantities of DNA templates were used to convert real-time qRT-PCR data into absolute (Lu et al., 2012). PCR generated templates were separated on an agarose gel and purified. Fluorometry (Promega QuantiFluor ${ }^{\mathrm{TM}}$ dsDNA system) was then used to determine the exact concentration in copies/ $\mu$ l of the templates. For each gene product a standard curve was constructed using a 10 -fold serial dilution series ranging from 1 to $1 \times 10^{8}$ copies/ $\mu \mathrm{L}$ of DNA template. Absolute values were then calculated using the standard curve equation of the line. To account for variations in starting RNA template these final absolute values in number of transcripts/ng of RNA were divided by the number of transcripts/ng of RNA of the reference gene 5FCL.

\section{PROTEIN GEL BLOT ANALYSIS}

Protein samples (total protein lysates, IWFs or petiole exudates concentrated by lyophilization) were mixed with 5X SDS loading buffer (350 mM Tris-HCL pH 6.8, 30\% glycerol, 10\% SDS, $0.01 \%$ bromophenol blue and 0, 5, $200 \mathrm{mM}$ DTT, followed by boiling for $5 \mathrm{~min}$. 2 to 4 individual lyophilized exudates were reconstituted in loading buffer $(5 \mathrm{mM}$ DTT in Figures 1, 2, Figures S1-S3; $200 \mathrm{mM}$ DTT in Figures 5-7, 9 and Figures S6, S9, S11, S12) and loaded per lane. Samples were loaded onto 4-12\% NuPAGE Bis-Tris polyacrylamide gels (Invitrogen) and subjected to electrophoresis in MES running buffer. Proteins were transferred to nitrocellulose membranes (Schleicher and Schuel) in Towbin transfer buffer $(25 \mathrm{mM}$ Tris base, $192 \mathrm{mM}$ glycine, 20\% methanol). Membranes were probed either with anti-DIR1 antisera (Maldonado et al., 2002) at a 1:20,000 dilution, anti-EGFP antibody (Clontech 63259) at 1:10000 dilution or anti-GUS antibody (Molecular Probes A5790) at 1:10,000 dilution in 5\% non-fat milk in TBST. Antibody binding was detected with a goat anti-rabbit horseradish peroxidase conjugate and WestFemto reagents (Pierce) as described by the manufacturer.

\section{BIOINFORMATICS}

Coding sequence and amino acid sequences of DIR1 (AT5G48485) and DIR1-like (AT5G48490) were retrieved from The Arabidopsis Information Resource (http://www.arabidopsis. org). Sequences were compared using the EMBOSS pairwise alignment algorithm (http://www.ebi.ac.uk/emboss/align). Signal peptides were deduced using the SignalP 3.0 prediction server at www.cbs.dtu.dk/services/SignalP. A SWISS-MODEL homology model of DIR1-like was produced using the Lascombe et al. (2008) DIR1-phosopholipid crystal structure as a template (Peitsch, 1995; Schwede et al., 2003; Arnold et al., 2006; Kiefer et al., 2009). The Swiss-pdf viewer 4.0.1 was used to compare the DIR1 structure and the DIR1-like protein model [http:/www.expasy.org/spdbv/] (Guex and Peitsch, 1997).

\section{PHYLOGENETIC ANALYSES}

A rooted phylogenetic Maximum Likelihood tree of DIR1 and DIR1-like proteins was created using protein sequences lacking the divergent ER signal sequence. Signal P 4.0 was used to determine where the signal sequence cleavage site was located (Perterson et al., 2011). The sequences were aligned in MEGA 5 using Muscle (Tamura et al., 2011). The evolutionary history was inferred using the Maximum Likelihood method based on the Kimura 2-parameter (Kimura, 1980) model with discrete Gamma distribution using MEGA 5 (Tamura et al., 2011). 10,000 bootstrap replicates were conducted and percent bootstrap values were placed on the branches (Felsenstein, 1985). Branches were drawn to scale, measured in number of substitutions per site and were labeled by species name followed by TAIR gene number or Phytozome 8.0 accession.

\section{SEE SUPPLEMENTARY METHODS FOR}

Construction of Agrobacterium strains and XVE:DIR1-EGFP transgenic lines and Recombinant protein production and DIR1antibody specificity testing.

\section{AUTHOR CONTRIBUTIONS}

Robin K. Cameron designed and orchestrated the research, performed a number of the petiole exudate/protein gel blot experiments and wrote most of the manuscript. All lab members performed petiole exudate experiments. Jennifer Faubert conceived of the distant leaf petiole exudate experiments, Marisa Isaacs conceived of and performed the DIR1-like homology modeling and DIR1/DIR1-like phylogeny. Marc J. Champigny contributed significantly to writing the manuscript, constructed the Agrobacterium 35S:DIR1-EYFP, DIR1-like, and EYFP lines and conceived of and constructed the transgenic XVE:DIR1-EGFP lines (Fobert Lab). Philip Carella and Marisa Isaacs conceived of and performed the experiments to test the specificity of the DIR1 antibody. Absolute quantitative RT-PCR experiments were performed by Marc J. Champigny and Jennifer Faubert in the Fobert lab and by Marisa Isaacs and Philip Carella in the Cameron lab.

\section{ACKNOWLEDGMENTS}

We thank ABRC for nprl-2 seeds. We thank John Stavrinides (U. Regina), Wilson Sung, and Yifei Huang (McMaster University) for useful discussions about parology, Daniel Yang (McMaster University) for advice on homology modeling, Robert Turgeon for advice about EDTA effects on petiole cell integrity and Zainab Rangwala (McMaster University) for contributing to the DIR1 phylogeny. Liquid Chromatography-Mass Spectroscopy/Mass Spectroscopy was performed by the Donald Danforth Plant Science Center for Proteomics and Mass Spectrometry Facility. This work was supported by grants to Robin K. Cameron (Natural Science and Engineering Research Council of Canada Discovery Grant and growth chamber maintenance support from McMaster University) and to Pierre R. Fobert (NSERC Discovery Grant).

\section{SUPPLEMENTARY MATERIAL}

The Supplementary Material for this article can be found online at: http://www.frontiersin.org/Plant-Microbe_ Interaction/10.3389/fpls.2013.00230/abstract 


\section{REFERENCES}

Agrios, G. N. (2005). Plant Pathology, 5th Edn. Burlington, MA: Elsevier Academic Press.

Arnold, K., Bordoli, L., Kopp, J., and Schwede, T. (2006). The SWISS-MODEL workspace: a web-based environment for protein structure homology modelling. Bioinformatics 22, 195-201. doi: 10.1093/bioinformatics/bti770

Attaran, E., Zeier, T. E., Grieel, T., and Zeier, J. (2009). Methyl Salicylate production and jasmonate signaling are not essential for systemic acquired resistance. Plant Cell 21, 954-971. doi: 10.1105/tpc.108.063164

Benghezal, M., Wasteneys, G. O., and Jones, D. A. (2000). The Cterminal dilysine motif confers endoplasmic reticulum localization to type-1 membrane proteins in plants. Plant Cell 12, 1179-1201.

Boutrot, F., Chantret, N., and Gautier, M. F. (2008). Genome-wide analysis of the rice and arabidopsis non-specific lipid transfer protein (nsLtp) gene families and identification of wheat nsLtp genes by EST data mining. BMC Genomics 9:86. doi: 10.1186/1471-2164-9-86

Cameron, R. K., Paiva, N. L., Lamb, C. J., and Dixon, R. A. (1999). Accumulation of salicylic acid and PR-1 gene transcripts in relation to systemic acquired resistance (SAR) response induced by Pseudomonas syringae pv. tomato in Arabidopsis. Physiol. Mol. Plant Pathol. 55, 121-130. doi: 10.1006/pmpp.1999.0214

Champigny, M. J., and Cameron, R. K. (2009). "Action at a distance: longdistance signals in induced resistance," in Plant Innate Immunity, Vol. 51, ed L. C. Van Loon (London: Academic Press), 123-171.

Champigny, M. J., Shearer, H., Mohammad, A., Haines, K., Neumann, M., Thilmony, R., et al. (2011). Localization of DIR1 at the tissue, cellular and subcellular levels during Systemic Acquired Resistance in Arabidopsis using DIR1:GUS and DIR1:EGFP reporters. BMC Plant Biol. 11:125. doi: 10.1186/1471-2229-11-125

Chanda, B., Xia, Y., Mandal, M. K., Yu, K., Sekine, K. T., Gao, Q. M., et al. (2011). Glycerol-3-phosphate is a critical mobile inducer of systemic immunity in plants. Nat. Genet. 43, 421-427. doi: 10.1038/ng.798

Chaturvedi, R., Krothapalli, K., Makandar, R., Nandi, A., Sparks, A. A., Roth, M. R., et al. (2008).
Plastid $\omega 3$-fatty acid desaturasedependent accumulation of a systemic acquired resistance inducing activity in petiole exudates of Arabidopsis thaliana is independent of jasmonic acid. Plant J. 54, 106-117. doi: 10.1111/j.1365313X.2007.03400.x

Chaturvedi, R., Venables, B., Petros, R., Nalam, V., Li, M., Wang, Z., et al. (2012). An abietane diterpenoid is a potent activator of systemic acquired resistance. Plant J. 71, 161-172. doi: 10.1111/j.1365313X.2012.04981.X

Chester, K. S. (1933). The problem of acquired physiological immunity in plants. Quart. Rev. Biol. 8, 275-324. doi: 10.1086/394440

Conrath, U. (2011). Molecular aspects of defence priming. Trends Plant Sci. 16, 524-534. doi: 10.1016/j.tplants.2011.06.004

Cui, J., Bahrami, A. K., Pringle, E. G., Hernandez-Guzman, G., Bender, C. L., Pierce, N. E., et al. (2005). Pseudomonas syringae manipulates systemic plant defenses against pathogens and herbivores. Proc. Natl. Acad. Sci. U.S.A. 102, 1791-1796. doi: 10.1073/pnas.0409450102

daSilva, L. L. P., Foresti, O., and Denecke, J. (2006). Targeting of the plant vacuolar sorting receptor BP80 Is dependent on multiple sorting signals in the cytosolic tail. Plant Cell 18, 1477-1497. doi: 10.1105/tpc.105.040394

Dempsey, D. A., and Klessig, D. F (2012). SOS - too many signals for systemic acquired resistance. Trends Plant Sci. 9, 538-545. doi: 10.1016/j.tplants.2012.05.011

Durrant, W. E., and Dong, X. (2004). Systemic acquired resistance. Annu. Rev. Phytopathol. 42, 185-209. doi: 10.1146/annurev. phyto.42.040803.140421

Felsenstein, J. (1985). Confidence limits on phylogenies: an approach using the bootstrap. Evolution 39, 783-791. doi: 10.2307/2408678

Fu, Z. Q., Yan, S. P., Saleh, A., Wang, W., Ruble, J., Oka, N., et al. (2012). NPR3 and NPR4 are receptors for the immune signal salicylic acid in plants. Nature 486, 228-232.

Gaffney, T., Friedrich, L., Vernooij, B., Negrotto, D., Nye, G., Uknes, S., et al. (1993). Requirement of salicylic acid for the induction of systemic acquired resistance. Science 261, 754-756. doi: 10.1126/science.261.5122.754

Gorjanović, S. (2007). Barley grain non-specific lipid-transfer proteins
(ns-LTPs) in beer production and quality. J. Inst. Brew. 113, 310-324. doi: 10.1002/j.2050 0416.2007.tb00291.x

Gorjanović, S., Spillner, E., Beljanski, M. V., Gorjanović, R., Pavlović, M., and Gojgić-Cvijanović, G. (2005). Malting barley grain non-specific lipid-transfer protein (ns-LTP): importance for grain protection. J. Inst. Brew. 111, 99-104. doi: 10.1002/j.20500416.2005.tb00654.x

Guedes, M. E. M., Richmond, S., and Kuć, J. (1980). Induced systemic resistance to anthracnose in cucumber as influenced by the location of the inducer inoculation with Colletotrichum lagenarium and the onset of flowering and fruiting. Physiol. Plant Pathol. 17, 229-233. doi: 10.1016 0048-4059(80)90056-9

Guelette, B. S., Benning, U. F., and Hoffmann-Benning, S. (2012). Identification of lipids and lipidbinding proteins in phloem exudates from Arabidopsis thaliana. J. Exp. Bot. 63, 3603-3616. doi: 10.1093/jxb/ers028

Guex, N., and Peitsch, M. C. (1997) SWISS-MODEL and the swisspdb viewer: an environment for comparative protein modeling. Electrophoresis 18, 2714-2723. doi: 10.1002/elps.1150181505

Hepler, P. K. (2005). Calcium: a central regulator of plant growth and development. Plant Cell 17, 2142-2155. doi: 10.1105/tpc.105. 032508

Hoh, F., Pns, J., Fautier, M., Lamotte, F. D., and Dumas, C. (2005) Structure of a liganded type 2 non-specific lipid-transfer protein from wheat and the molecular basis of lipid binding. Biol. Cristallogr. 61, 397-406. doi: 10.1107/S0907444905000417

Jenns, A. E., and Kuć, J. (1979). Graft transmission of systemic resistance of cucumber to anthracnose induced by Colletotrichum lagenarium and tobacco necrosis virus. Phytopathology 69, 753-756. doi: 10.1094/Phyto-69-753

Jung, H. W., Tschaplinski, T. J., Wang, L., Glazebrook, J., and Greenberg, J. T. (2009). Priming in systemic plant immunity. Science 324, 89-91. doi: 10.1126/science. 1170025

Kiefer, F., Arnold, K., Künzli, M. Bordoli, L., and Schwede, T. (2009). The SWISS-MODEL Repository and associated resources. Nucleic Acids Res. 37, D387-D392. doi: 10.1093/nar/gkn750
Kiefer, I. W., and Slusarenko, A. J. (2003). The pattern of systemic acquired resistance induction within the Arabidopsis rosette in relation to the pattern of translocation. Plant Physiol. 132, 840-847. doi: 10.1104/pp.103.021709

Kimura, M. (1980). A simple method for estimating evolutionary rates of base substitutions through comparative studies of nucleotide sequences. J. Mol. Evol. 16, 111-120. doi: 10.1007/BF01731581

King, W., and Zeevaart, J. A. D. (1974). Enhancement of phloem exudation from cut petioles by chelating agents. Plant Physiol. 53, 96-103. doi: $10.1104 / p p .53 .1 .96$

Kuć, J. (1982). Induced immunity to plant disease. Bioscience 32, 854-856. doi: 10.2307/1309008

Kus, J. V., Zaton, K., Sarkar, R., and Cameron, R. K. (2002). Agerelated resistance in Arabidopsis is a developmentally regulated defense response to Pseudomonas syringae. Plant Cell 14, 479-490. doi: 10.1105/tpc.010481

Lascombe, B., Buhot, N., Bakan, B., Marion, D., Blein, J. P., Lamb, C., et al. (2006). Crystallization of DIR1, a LTP2-like resistance signalling protein from Arabidopsis thaliana. Acta Crystallogr. Sect. F Struct. Biol. Cryst. Commun. 62, 702-704. doi: 10.1107/S1744309106023748

Lascombe, M. B., Bakan, B., Buhot, N., Marion, D., Blein, J. P., Larue, V., et al. (2008). The structure of "defective in induced resistance" protein of Arabidopsis thaliana, DIR1, reveals a new type of lipid transfer protein. Protein Sci. 17, 1522-1530. doi: 10.1110/ps.035972.108

Liu, P. P., Bhattacharjee, S., Klessig, D. F., and Moffett, P. (2010a). Systemic acquired resistance is induced by $\mathrm{R}$ gene-mediated responses independent of cell death. Mol. Plant Path. 11, 155-160. doi: 10.1111/j.13643703.2009.00564.x

Liu, P. P., Yang, Y., Pichersky, E., and and Klessig, D. F. (2010b). Altering expression of benzoic acid/salicylic acid carboxyl methyltransferase 1 compromises systemic acquired resistance and PAMP-triggered immunity in Arabidopsis. Mol. Plant Microbe. Interact. 23, 82-90. doi: 10.1094/MPMI-23-1-0082

Liu, P., von Dahl, C. C., Park, S., and Klessig, D. F. (2011a). Interconnection between methyl salicylate and lipid-based longdistance signaling during the development of systemic 
acquired resistance in arabidopsis and tobacco. Plant Physiol. 155, 1762-1768. doi: 10.1104/pp.110.171694

Liu, P. P., von Dahl, C. C., and Klessig, D. F. (2011b). The extent to which methyl salicylate is required for signaling systemic acquired resistance is dependent on exposure to light after infection. Plant Physiol. 157, 2216-2226. doi: 10.1104/pp.111.187773

Lu, Y., Xie, L., and Chen, J. (2012). A novel procedure for absolute realtime quantification of gene expression patterns. Plant Methods 8, 1-11. doi: 10.1186/1746-4811-8-9

Mahler, H.-C., Friess, W., Grauschopf, U., and Kiese, S. (2009). Protein aggregation: pathways, induction factors and analysis. J. Pharm. Sci. 98, 2909-2934. doi: 10.1002/jps.21566

Malamy, J., Carr, J. P., Klessig, D. F., and Raskin, I. (1990). Salicylic acid: a likely endogenous signal in the resistance response of tobacco to viral infection. Science 250, 1002-1004. doi: 10.1126/science.250.4983.1002

Maldonado, A. M., Doerner, P., Dixon, R. A., Lamb, C. J., and Cameron, R. K. (2002). A putative lipid transfer protein involved in systemic resistance signalling in Arabidopsis. Nature 419, 399-402. doi: 10.1038/nature00962

Métraux, J.-P., Signer, H., Ryals, J., Ward, E., Wyss-Benz, M., Gandin, J., et al. (1990). Increase in salicylic acid at the onset of systemic acquired resistance in cucumber. Science 250, 1004-1006. doi: 10.1126/science.250.4983.1004

Misas-Villamil, J. C., and $\mathrm{Al}$ van der Hoorn, R. (2008). Enzymeinhibitor interactions at the plant-pathogen interface. Curr. Opin. Plant Biol. 11, 380-388. doi: 10.1016/j.pbi.2008.04.007

Mishina, T., and Zeier, J. (2007). Pathogen-associated molecular pattern recognition rather than development of tissue necrosis contribute to bacterial induction of systemic acquired resistance in Arabidopsis. Plant J. 50, 500-513. doi: 10.1111/j.1365-313X.2007.03067.x

Mitton, F. M., Pinedo, M. L., and de Canal, L. (2009). Phloem sap of tomato plants contains a DIR1 putative ortholog. J. Plant Physiol. 166, 543-547. doi: 10.1016/j.jplph.2008.07.002

Moore, I., Samalova, M., and Kurup, S. (2005). Transactivated and chemically inducible gene expression in plants. Plant J. 45,
651-683. doi: 10.1111/j.1365313X.2006.02660.x

Nandi, A., Welti, R., and Shah, J. (2004). The Arabidopsis thaliana dihydroxyacetone phosphate reductase gene suppressor of fatty acid desaturase deficiencyl is required for glycerolipid metabolism and for the activation of systemic acquired resistance. Plant Cell 16, 465-477. doi: 10.1105/tpc.016907

Nimchuk, Z., Marois, E., Kjemtrup, S., Leister, R. A., Katagiri, F., and Dangl, J. (2000). Eukaryotic fatty acylation drives plasma membrane targeting and enhances function of several type III effector proteins from Pseudomonas syringae. Cell 101, 353-363. doi: 10.1016/S00928674(00)80846-6

Pallas, J. A., Paiva, N. L., Lamb, C., Dixon, R. A. (1996). Tobacco plants epigenetically suppressed in phenylalanine ammonia-lyase expression do not develop systemic acquired resistance in response to infection by tobacco mosaic virus. Plant J. 10, 281-293. doi: 10.1046/j.1365313X.1996.10020281.x

Parker, J. E. (2009). The quest for longdistance signals in plant systemic immunity. Sci. Signal. 2, 31. doi: 10.1126/scisignal.270pe31

Park, S.-W., Kaimoyo, E., Kumar, D., Mosher, S., and Klessig, D. F. (2007). Methyl Salicylate is a critical mobile signal for plant systemic acquired resistance. Science 318, 113-116. doi: 10.1126/science.1147113

Pasquato, N., Berni, R., Folli, C., Folloni, S., Cianci, M., Pantano, S., et al. (2005). Crystal structure of peach Prup3, the prototypic member of the family of plant non-specific lipid transfer protein pan-allergens. J. Mol. Biol. 356, 684-694. doi: 10.1016/j.jmb. 2005.11.063

Peitsch, M. C. (1995). Protein modeling by E-mail. Nat. Biotechnol. 13, 658-660. doi: 10.1038/ nbt0795-658

Perterson, T. N., Brunak, S., von Heijne, G., Nielsen, H. (2011). SignalP 4.0: discriminating signal peptides from transmembrane regions. Nat. Methods 8, 785-786. doi: $10.1038 /$ nmeth.1701

Rasmussen, J. B., Hammerschmidt, R., and Zook, M. N. (1991). Systemic induction of salicylic acid accumulation in cucumber after inoculation with Pseudomonas syringae pv syringae. Plant Physiol. 97, 1342-1347. doi: 10.1104/pp.97.4.1342

Ross, A. F. (1961). Systemic acquired resistance induced by localized virus infections in plants. Virology 14, 340-358. doi: 10.1016/0042-6822(61)90319-1

Rutledge, R. G., and Stewart, D. (2008). A kinetic-based sigmoida model for the polymerase chain reaction and its application to high-capacity absolute quantitative real-time PCR. BMC Biotechnol. 8:47. doi: 10.1186/1472 6750-8-47

Schranz, M. E., Song, B., Windsor, A. J., and Mitchell-Olds, T. (2007). Comparative genomics in the Brassicaceae: a familywide perspective. Curr. Opin. Plant Biol. 10, 168-175. doi 10.1016/j.pbi.2007.01.014

Schwede, T., Kopp, J., Guex, N. and Peitsch, M. (2003). SWISSMODEL: an automated protein homology-modeling server. Nucleic Acids Res. 31, 3381-3385. doi: $10.1093 /$ nar/gkg520

Shah, J., and Zeier, J. (2013). Long distance communication and signal amplification in systemic acquired resistance. Front. Plant Sci. 4:30. doi: 10.3389/fpls.2013.00030

Tamura, K., Peterson, D., Peterson, N., Stecher, G., Nei, M., and Kumar, S. (2011). MEGA5: molecular evolutionary genetics analysis using maximum likelihood, evolutionary distance, and maximum parsimony methods. Mol. Biol. Evol. 28, 2731-2739. doi: 10.1093/molbev/msr121

Truman, W., Bennett, M. H., Kubogsteltig, I., Turnbull, C., and Grant, M. (2007). Arabidopsis systemic immunity uses conserved defense signaling pathways and is mediated by jasmonates. Proc. Natl. Acad. Sci. U.S.A. 104, 1075-1080. doi: 10.1073/pnas. 0605423104

Tsuda, K., Qi, Y., Nguyen, L. V., Bethke, G., Tsuda, Y., Glazebrook, J., et al. (2012). An efficient Agrobacterium-mediated transient transformation of Arabidopsis. Plant J. 69, 713-719. doi: 10.1111/j.1365-313X.2011.04819.x

Tuzun, S., and Kuć, J. (1985). Movement of a factor in tobacco infected with Peronospora tabacina Adam which systemically protects against blue mold. Physiol. Plant Pathol. 26, 321-330. doi: 10.1016/0048-4059(85)90007-4

Uknes, S., Mauch-Mani, B., Moyer, M., Potter, S., Williams, S., Dincher, S., et al. (1992). Acquired resistance in Arabidopsis. Plant Cell 4, 645-656.

van Loon, L. C., and van Strien, E. A. (1999). The families of pathogenesis-related proteins, their activities, and comparative analysis of PR-1 type proteins. Physiol. Mol. Plant Pathol. 55, 85-97.

Vernooij, B., Friedrich, L., Morse, A., Reist, R., Kolditz-Jawhar, R., Ward, E., et al. (1994). Salicylic acid is not the translocated signal responsible for inducing systemic acquired resistance but is required in signal transduction. Plant Cell 6, 959-965.

Vlot, A. C., Liu, P. P., Cameron, R. K., Park, S. W., Yang, Y., Kumar, D., et al. (2008). Identification of likely orthologs of tobacco salicylic acid-binding protein 2 and their role in systemic acquired resistance in Arabidopsis thaliana. Plant J. 56, 445-456. doi: 10.1111/j.1365313X.2008.03618.x

Whalen, M. C., Innes, R. W., Bent, A. F., and Staskawicz, B. J. (1991) Identification of Pseudomonas syringae pathogens of Arabidopsis and a bacterial locus determining avirulence on both Arabidopsis and soybean. Plant Cell 3, 49-59.

Williamson, M. P. (1994). The structure and function of proline-rich regions in proteins. Biochem. J. 297, 249-260.

Wroblewski, T., Tomczak, A. and Michelmore, R. (2005). Optimization of Agrobacteriummediated transient assays of gene expression in lettuce, tomato and Arabidopsis. Plant Biotechnol. J. 3, 259-273. doi: 10.1111/j.1467-7652.2005.00123.x

Wu, Y., Zhang, D., Chu, J. Y., Boyle, P., Wang, Y., Brindle, I. D., et al. (2012). The Arabidopsis NPR1 protein is a receptor for the plant defense hormone salicylic acid. Cell Rep. 1, 639-647. doi: 10.1016/j.celrep.2012.05.008

Xia, Y., Suzuki, H., Borevitz, J., Blount, J., Guo, Z., Patel, K., et al. (2004). An extracellular aspartic protease functions in Arabidopsis disease resistance signaling. EMBO J. 23, 980-988. doi: 10.1038/sj.emboj.7600086

Yeats, T. H., and Rose, J. K. C. (2008). The biochemistry and biology of extracellular plant lipid-transfer proteins (LTPs). Protein Sci. 17, 191-198. doi: 10.1110/ps.073300108

Zipfel, C., Kunze, G., Chinchilla, D., Caniard, A., and Jones, J. D. G. (2006). Perception of the bacterial PAMP ER-Tu by the receptor EFR restricts Agrobacterium-mediated transformation. Cell 125, 749-760. doi: 10.1016/j.cell.2006.03.037 
Zuo, J., Niu, Q. W., and Chua, N. H. (2000). Technical advance: an estrogen based-receptor transactivator XVE mediates highly inducible gene expression in transgenic plants. Plant J. 24, 265-273. doi: 10.1046/j.1365-313x.2000.00868.x

Conflict of Interest Statement: The authors declare that the research was conducted in the absence of any commercial or financial relationships that could be construed as a potential conflict of interest.

Received: 14 February 2013; accepted: 12 June 2013; published online: 04 July 2013

Citation: Champigny MJ, Isaacs $M$, Carella $P$, Faubert $J$, Fobert
$P R$ and Cameron RK (2013)

Long distance movement of DIR1 and investigation of the role of DIR1-like during systemic acquired resistance in Arabidopsis. Front. Plant Sci. 4:230. doi: 10.3389/fpls. 2013.00230

This article was submitted to Frontiers in Plant-Microbe Interaction, a specialty of Frontiers in Plant Science.
Copyright (C) 2013 Champigny, Isaacs, Carella, Faubert, Fobert and Cameron. This is an open-access article distributed under the terms of the Creative Commons Attribution License, which permits use, distribution and reproduction in other forums, provided the original authors and source are credited and subject to any copyright notices concerning any third-party graphics etc. 